\title{
Chromatin remodeler CHD7 regulates the stem cell identity of human neural progenitors
}

\author{
MuhChyi Chai, ${ }^{1,2,6}$ Tsukasa Sanosaka, ${ }^{1,6}$ Hironobu Okuno, ${ }^{1}$ Zhi Zhou, ${ }^{1}$ Ikuko Koya, ${ }^{1}$ Satoe Banno, ${ }^{1}$ \\ Tomoko Andoh-Noda, ${ }^{1}$ Yoshikuni Tabata, ${ }^{1,3}$ Rieko Shimamura, ${ }^{1}$ Tetsutaro Hayashi, ${ }^{4}$ \\ Masashi Ebisawa, ${ }^{4}$ Yohei Sasagawa, ${ }^{4}$ Itoshi Nikaido, ${ }^{4,5}$ Hideyuki Okano, ${ }^{1}$ and Jun Kohyama ${ }^{1}$ \\ ${ }^{1}$ Department of Physiology, Keio University School of Medicine, Shinjuku-ku, Tokyo 160-8582, Japan; ${ }^{2}$ Gene Regulation Research, \\ Nara Institute of Science and Technology, Ikoma, Nara 630-0101, Japan; ${ }^{3}$ E-WAY Research Laboratory, Discovery, Medicine \\ Creation, Neurology Business Group, Tsukuba, Ibaraki 300-2635, Japan; ${ }^{4}$ Bioinformatics Research Unit, Advanced Center for \\ Computing and Communication, RIKEN, Wako, Saitama 351-0198, Japan; ${ }^{5}$ Single-Cell Omics Research Unit, RIKEN Center for \\ Developmental Biology, Wako, Saitama 351-0198, Japan
}

\begin{abstract}
Multiple congenital disorders often present complex phenotypes, but how the mutation of individual genetic factors can lead to multiple defects remains poorly understood. In the present study, we used human neuroepithelial (NE) cells and CHARGE patient-derived cells as an in vitro model system to identify the function of chromodomain helicase DNA-binding 7 (CHD7) in NE-neural crest bifurcation, thus revealing an etiological link between the central nervous system (CNS) and craniofacial anomalies observed in CHARGE syndrome. We found that CHD7 is required for epigenetic activation of superenhancers and CNS-specific enhancers, which support the maintenance of the NE and CNS lineage identities. Furthermore, we found that BRN2 and SOX21 are downstream effectors of CHD7, which shapes cellular identities by enhancing a CNS-specific cellular program and indirectly repressing nonCNS-specific cellular programs. Based on our results, CHD7, through its interactions with superenhancer elements, acts as a regulatory hub in the orchestration of the spatiotemporal dynamics of transcription factors to regulate $\mathrm{NE}$ and CNS lineage identities.
\end{abstract}

[Keywords: CHARGE syndrome; CHD7; ChIP-seq; neural progenitors; neural crest; superenhancers]

Supplemental material is available for this article.

Received May 11, 2017; revised version accepted January 2, 2018.

Chromatin-based epigenetic alterations are responsible for multiple human neurodevelopmental disorders, including Coffin-Siris syndrome, autism, a thalassemia Xlinked intellectual retardation (ATRX) syndrome, Kabuki syndrome, and Rett syndrome (Ronan et al. 2013), suggesting that chromatin regulators play important roles in neural development. CHARGE syndrome is a congenital disorder with multiple features caused by heterozygous mutation of chromodomain helicase DNA-binding 7 (CHD7) (Vissers et al. 2004). Currently, no effective treatment is available for this disease. CHD7 is a member of the CHD family, a group of ATP-dependent chromatin remodeling factors that alter chromatin structure by rearranging the position and organization of nucleosomes on DNA (Jiang and Pugh 2009).

CHARGE syndrome is commonly known as a neural crest $(\mathrm{NC})$ disease or neurocristopathy in which NC-de-

\footnotetext{
${ }^{6}$ These authors contributed equally to this work.

Corresponding authors: hidokano@keio.jp, jkohyama@a7.keio.jp Article published online ahead of print. Article and publication date are online at http://www.genesdev.org/cgi/doi/10.1101/gad.301887.117.
}

rived tissues are defective. CHD7 knockdown human embryonic stem cells (ESCs) consistently fail to differentiate into NC-like cells, indicating that CHD7 is required for NC specification and migration (Bajpai et al. 2010). Several studies of experimental mouse models have reported that Chd7 is essential for neurogenesis (Layman et al. 2009; Jiang et al. 2012; Feng et al. 2013; Yu et al. 2013; Jones et al. 2015) and acts as an upstream activator of the promoters of several neurogenic genes, such as Sox4, Sox11, and Gli3 (Engelen et al. 2011; Feng et al. 2013). Moreover, Chd7 plays a pivotal role in the regulation of oligodendrocyte maturation and myelination $(\mathrm{He}$ et al. 2016), substantiating a potentially important function of Chd7 in central nervous system (CNS) development. Given that CHD7 depletion adversely affects the capacity for differentiation toward both neural and NC lineages, it is

(C) 2018 Chai et al. This article is distributed exclusively by Cold Spring Harbor Laboratory Press for the first six months after the full-issue publication date (see http://genesdev.cshlp.org/site/misc/terms.xhtml). After six months, it is available under a Creative Commons License (Attribution-NonCommercial 4.0 International), as described at http://creativecommons.org/licenses/by-nc/4.0/. 
conceivable that $\mathrm{CHD} 7$ is a regulator of cell type-specific gene expression programs. Consistent with this idea, genome-wide ChIP-seq (chromatin immunoprecipitation [ChIP] followed by sequencing) analysis of Chd7 using mouse ESCs revealed that Chd7 regulates the establishment of an ESC-specific gene expression program through binding to enhancer elements, and Chd7-binding preferences change during the transition from ESCs to neural progenitors, indicating that the function of Chd7 varies by developmental stage (Schnetz et al. 2009, 2010).

To date, the functional roles of Chd7 have been examined mainly in adult neural stem cells and lineage-committed progenitors from animal models; however, CHD7 is highly enriched in the neural tube, a key structure in neuroectodermal development of the human fetal brain (Sanlaville et al. 2006). Importantly, CHD7 expression is confined to the CNS and mesenchymal structures (Sanlaville et al. 2006), both of which originate from the neuroectoderm. Although CNS and craniofacial anomalies frequently co-occur in CHARGE patients (Sanlaville and Verloes 2007), no study to date has addressed the impact of CHD7 dysfunction on human neuroectodermal development. These deficits in knowledge of the molecular functions of CHD7 and the importance of CHD7-dependent regulation in the etiology of CHARGE syndrome highlight the need for an investigation focused on developmental stages relevant to CHARGE pathogenesis.

In the present study, we used induced pluripotent stem cell-derived neuroepithelial (iPSC-NE) cells, which exhibit cellular properties equivalent to those of early NE precursors residing in the neural tube (Koch et al. 2009; Falk et al. 2012), as an in vitro model to evaluate the function of CHD7 during neuroectodermal development. By establishing iPSC-NE cells from healthy donors and CHARGE patients, we found that CHD7 plays an essential role in maintaining NE identity and CNS lineage development by indirectly suppressing the induction of the NC. Furthermore, we found that CHD7 controls an epigenetic state that maintains CNS lineage identity largely through the activation of CNS-specific enhancers. Moreover, we show that CHD7-dependent superenhancer (SE) activation controls the expression of SOX21 and BRN2, which are functionally important in the maintenance of NE identity as well as for the pathogenesis of CHARGE syndrome.

\section{Results}

NE cells express higher levels of CHD7 than NC cells (NCCs)

To explore the function of CHD7 in NE cells, we initially examined the expression of CHD7 in iPSC-derived neural rosettes (Curchoe et al. 2012), which are highly organized multicellular structures of NE cells. As shown in Figure 1A, we observed CHD7 expression in SOX1- and SOX2positive neural rosettes. We also observed intense $\mathrm{CHD} 7$ expression in most SOX1- and Nestin-positive NE cells (Fig. 1A). Following neuronal differentiation of NE cells, CHD7 expression remained enriched in $\beta$ III-tubulin-positive neurons but was faintly detectable only in NeuN-pos- itive mature neurons (Fig. 1A), consistent with previous in vivo data showing that the expression of Chd7 is turned off in mouse dentate gyrus granule neurons and cerebellar Purkinje neurons (Jones et al. 2015; Habib et al. 2016; Feng et al. 2017). We further examined the expression of CHD7 in brain organoids derived from iPSCs (Lancaster et al. 2013) and observed that CHD7 expression was decreased in NeuN-positive neurons (Fig. 1A). These results indicate that the expression of CHD7 is functionally required before terminal differentiation of NE cells. Given the morphological and structural resemblance between the neural rosette and embryonic neural tube, CHD7 expression in NE cells recapitulates the in vivo expression of CHD7 in the neural tubes of human fetal brains (Sanlaville et al. 2006). Since CHARGE syndrome is commonly considered a neurocristopathy and CHD7 is required for the formation of the migratory NC (Bajpai et al. 2010), we next sought to compare the expression levels of CHD7 between iPSC-derived AP-2a-positive NCCs and NE cells. The CHD7 expression level was lower in NCCs than in NE cells (Fig. 1B). We further sought to compare the expression level of Chd7 between NCCs and NE cells by performing immunohistochemistry in mouse embryonic day 10.5 (E10.5) neural tube sections. In vivo, the expression level of Chd7 in Sox1-positive NE cells was visibly higher than that in p75- or Zic1/2positive migrating NCCs (Achilleos and Trainor 2012; Simoes-Costa and Bronner 2013) located outside the neural tube (Fig. 1C). Taking our in vivo and in vitro data together, we hypothesized that higher levels of CHD7 in NE cells define NE fate.

\section{CHD7 is required for the maintenance of NE identity}

Next, to ascertain whether the expression level of CHD7 defines NE fate, we conducted lentiviral shRNA-mediated knockdown of CHD7 in NE cells (AF22 cell line). Two different shRNAs against CHD7 were used, and the knockdown efficiency of CHD7 was validated by immunocytochemistry and quantitative RT-PCR (qRT-PCR) (Supplemental Fig. S1A,B). In the presence of CHD7 shRNAs, the number of cells expressing definitive NE markers, including SOX1 and DACH1 (Koch et al. 2009), was markedly reduced, indicating that knockdown of CHD7 resulted in the loss of NE identity (Fig. 1D).

Since previous studies have shown that NE cells are highly neurogenic and predominantly give rise to neurons (Koch et al. 2009), we next addressed whether CHD7 knockdown cells retain their neurogenic potential despite the loss of NE identity. To accelerate the neuronal differentiation of transduced NE cells, we treated the cells with CHIR-99021 (CHIR), a small-molecule inhibitor of glycogen synthase kinase 3 (GSK-3), prior to induction of terminal neuronal differentiation (Fig. 1E; Li et al. 2011; Shimojo et al. 2015). NE cells carrying control shRNA differentiated into $\beta$ III-tubulin-positive neurons, and some coexpressed NeuN (Fig. 1E). In contrast, both $\beta$ III-tubulin-positive and NeuN-positive neurons derived from CHD7 knockdown NE cells were decreased (Fig. 1E). Interestingly, concomitant with the loss of neurogenic 

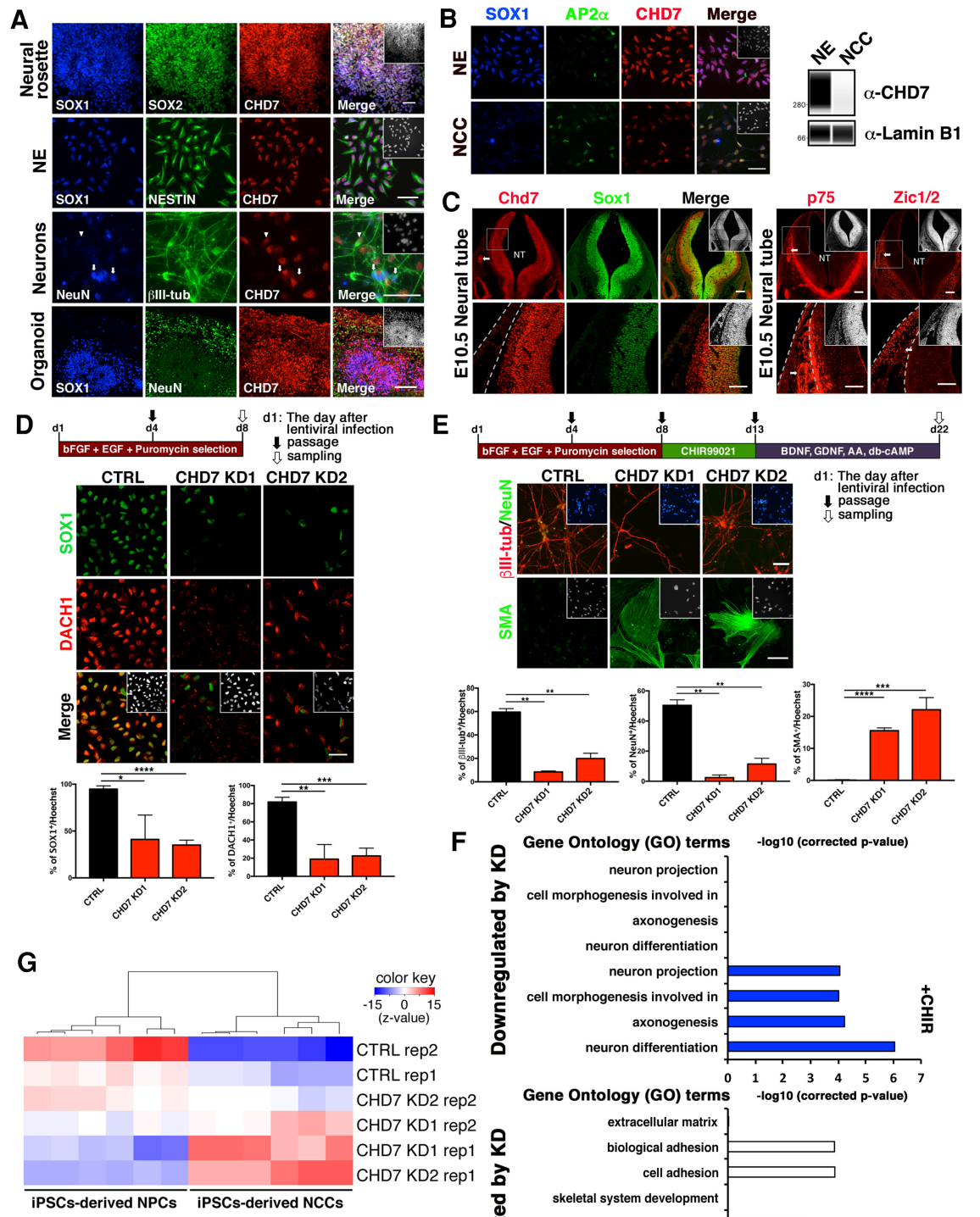

$\mathbf{F}$

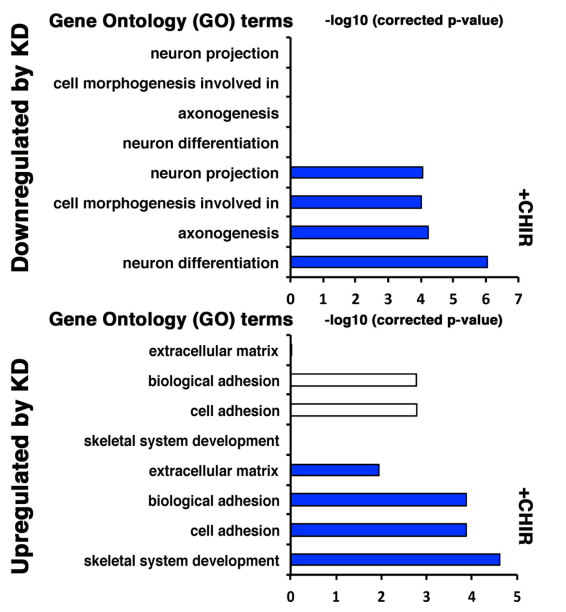

Figure 1. CHD7 is highly expressed in NE cells. (A) Immunocytochemistry showing that human iPSC-derived neural rosettes (first panel) express SOX1 (blue), SOX2 (green), and $\mathrm{CHD} 7$ (red) at day 5 of neural induction and that the neural rosettes expanded as monolayer cultures (second panel) are positive for SOX1 (blue), Nestin (green), and CHD7 (red). Immunocytochemistry of human NE-derived neuronal cells (third panel) showing that immature neuronal cells are positive for both $\beta I I I-t u-$ bulin (green) and CHD7 (red) (indicated by an arrowhead), whereas mature $\mathrm{NeuN}^{+}$ neuronal cells (blue) do not coexpress CHD7 (indicated by arrows). Immunocytochemistry of 60-d-old human iPSC-derived brain organoids (fourth panel) for SOX1 (blue), NeuN (green), and CHD7 (red). NE cells express $\mathrm{CHD} 7$, whereas mature neuronal cells are depleted of CHD7 expression. (Insets) Hoechst nuclear staining of each field. Bars, $50 \mu \mathrm{m}$. (B) Immunocytochemistry of NE cells and human iPSC-derived NCCs for SOX1 (blue), AP-2a (green), and $\mathrm{CHD} 7$ (red). (Insets) Hoechst nuclear staining of each field. Bars, $50 \mu \mathrm{m}$. Immunoblot analysis of $\mathrm{CHD} 7$ expression in NE cells and NCCs. (Right panel) Lamin B1 was used as a nuclear loading control. $(C, t o p$ left panel) Immunostaining for Chd7 and Sox1 of E10.5 neural tube sections. (Top right panel) Immunostaining for migratory NC markers (p75 and Zic1/2) of E10.5 neural tube sections. The small boxes in the top panels denote magnified regions shown in the bottom panels. The arrow points to a neurogenic dorsal root ganglion (DRG) cluster. (Insets) Hoechst nuclear staining of each field. Bars, $50 \mu \mathrm{m}$. (NT) Neural tube. $(D$, top panel) Schematic diagram illustrating fixation and analysis of CHD7 knockdown cells. (Middle panel) Immunocytochemistry for SOX1 and DACH1 expression in NE cells. (Insets) Hoechst nuclear staining of each field. Bars, $50 \mu \mathrm{m}$. Quantification of the number of SOX1-
SEM. $\left(^{*}\right) P<0.05 ;\left(^{* *}\right) P<0.01 ;\left({ }^{* * *}\right)$ and DACH1-expressing cells is shown in the bottom panel. $n=3$. Data are presented as the mean \pm SEM. $\left({ }^{*}\right) P<0.05 ;\left({ }^{* *}\right) P<0.01 ;\left({ }^{* * *}\right)$ $P<0.001 ;\left({ }^{* * *}\right) P<0.0001$, two-tailed unpaired Student's $t$-test. (E, top panel) Schematic of the neuronal differentiation protocol. (Middle panel) Immunostaining of control and CHD7 knockdown cells after neuronal differentiation (at day 22) for $\beta$ III-tubulin, NeuN, and smooth muscle actin (SMA). (Insets) Hoechst nuclear staining of each field. Bars, $50 \mu \mathrm{m}$. Quantification of the number of neuronal cells and smooth muscle cells is shown in the bottom panel. $n=3$. Data are presented as the mean \pm SEM. $\left(^{* *}\right) P<0.01 ;\left({ }^{* * *}\right) P<0.001 ;\left({ }^{* * * *}\right) P<$ 0.0001 , two-tailed unpaired Student's $t$-test. $(F)$ Bar plot of the top four gene ontology (GO) terms for genes down-regulated (top panel) and up-regulated (bottom panel) by CHD7 knockdown in CHIR-99021 (CHIR)-treated NE cells. Enrichment of corresponding GO terms in NE cells is also shown. $(G)$ Heat map representation of the correlation of the gene expression of CHIR-treated control and CHD7 knockdown NE cells with the gene expression of iPSC-derived neural progenitor cells (NPCs) and iPSCs-NCCs. The color indicates the $z$-value for correlation significance.

potential, CHD7 knockdown induced the emergence of smooth muscle actin (SMA)-expressing cells under neurogenic conditions (Fig. 1E); this identity is at odds with NE cells, which are classically known as CNS stem cells that differentiate mainly into neurons, astrocytes, and oligodendrocytes. When stimulated, NE precursor cells are ca- pable of redirecting their commitment to the NC lineage in a temporally dependent manner in avian embryos (Scherson et al. 1993). Thus, we speculated that the emergence of SMA-expressing cells instead of neuronal differentiation after CHD7 knockdown was a result of a fate switch to the NC lineage. 
Chai et al.

\section{CHD7 knockdown NE cells acquire the transcriptional} signatures of NCCs

To confirm whether CHD7 reduction leads to altered lineage identity, we generated and compared transcriptome profiles from control and CHD7 knockdown NE cells before and immediately after CHIR treatment (day 8 and day 13 , respectively). We reasoned that transcriptional dysregulation of lineage-specific markers might be enhanced in the progression toward differentiation. Gene ontology (GO) analysis showed that "neuron differentiation," "axonogenesis," and "neuron projection" were among the top biological functions down-regulated in CHIR-treated shCHD7-expressing cells, whereas "skeletal system development," "cell and biological adhesion," and "extracellular matrix" were among the main biological functions up-regulated in these cells (Fig. 1F). Notably, a subset of dysregulated NC signature genes was preferentially enriched in the GO term associated with "skeletal system development" (Simoes-Costa and Bronner 2013), and we further validated the up-regulation of some of these transcription factors (TFs), including TWIST1 (SaukaSpengler and Bronner-Fraser 2008), SNAI2 (Nieto et al. 1994; Thomas et al. 2008), and MSX1/2 (Hill et al. 1989; Nikitina et al. 2008), by qRT-PCR analyses (Supplemental Fig. S1C). These results suggest that acquisition of NC-like identity occurs as a consequence of the loss of NE identity. To further validate this finding, we analyzed whether the gene expression program evolved from NE-specific to NC-specific in CHD7 knockdown cells by using pairwise correlation of neural progenitor cell (NPC)-enriched and NCC-enriched genes extracted from publicly available data sets (Fig. 1G). The global gene expression profiles of CHD7 knockdown cells were more similar to those of NCCs than those of NPCs; conversely, control knockdown cells remained closely correlated to NPCs (Fig. 1G).

Our current data suggest that at the end of CHIR treatment, the NC-specific gene expression program that reinforces NC identity was activated in CHD7 knockdown cells. To determine the earliest timing of transition into NC-like cells, we examined NE cells at $8 \mathrm{~d}$ (passage 1) and $12 \mathrm{~d}$ (passage 2) after transduction with lentiviruses expressing CHD7 shRNA or control shRNA for the ectopic expression of SOX9 and SNAIL. Forced expression of these two TFs is sufficient to induce NC-like characteristics and promote epithelial-mesenchymal transition of NE cells, ultimately leading to inhibition of CNS neuronal generation (Cheung and Briscoe 2003; Cheung et al. 2005). As shown in Supplemental Figure S1D, immunocytochemistry and qRT-PCR analyses collectively showed that SOX9 and SNAI2 were up-regulated in cells expressing $C H D 7$ shRNA as early as day 8 and persisted until day 12 after transduction in NE maintenance medium. Indeed, discernible changes in NE cell morphology that comprised the loss of rosette-like patterns and the acquisition of mesenchymal-like loosely packed structures were observed the day after the first passage (day 5) (data not shown). Together, our findings suggest that a high expression level of CHD7 is directly correlated with NE identity. Failure to maintain a robust CHD7 level triggered a rapid cell fate switch, as shown by the manifestation of transcriptional and morphological features of NCCs upon CHD7 knockdown. We further performed single-cell RNA sequencing (RNA-seq) analysis to examine differential gene expression associated with $\mathrm{CHD} 7$ reduction and found that the transition of NE cells to NCCs was likely to occur even at single-cell resolution (Supplemental Fig. S2). Together, these data suggest that the loss of NE identity and the subsequent conversion of CNS stem cells to non-CNS cells likely cause prevalent terminal differentiation defects in $\mathrm{Chd} 7^{-/}$mouse neural progenitors in vivo (Feng et al. 2013, 2017; He et al. 2016).

\section{CHD7 haploinsufficiency underlies inappropriate lineage commitment}

To confirm whether the above lineage defect is relevant in patient-derived NE cells, we obtained NE cells from iPSCs derived from two individual CHARGE patients (Okuno et al. 2017) and two unrelated healthy control individuals (referred to here as wild type) (Takahashi et al. 2007; Isoda et al. 2016). The first CHARGE syndrome patient was heterozygous for $\mathrm{CHD} 7^{\mathrm{Gln} 1391 \mathrm{fs}}\left(\mathrm{CHD} 7^{\mathrm{G} 1391 \mathrm{fs} /{ }^{+}}\right.$; referred to here as $\mathrm{CH} 1$ ), and the second patient was heterozygous for $\mathrm{CHD}{ }^{\mathrm{Arg} 1494 \mathrm{X}}\left(\mathrm{CHD}^{\mathrm{R} 1494 \mathrm{X} /{ }^{+}}\right.$; referred to here as $\mathrm{CH} 2)$ (Fig. 2A). Both frameshift and nonsense mutations lead to premature termination of $\mathrm{CHD} 7$, which is predicted to undergo degradation by nonsense-mediated decay (NMD) (Zentner et al. 2010). Consistently, we found that CHD7 mRNA and protein were reduced in patient-derived iPSCs compared with those in wild-type iPSCs (Supplemental Fig. S3A,B). To examine their differentiation capacity, we generated NE cells from wild-type and patient-derived iPSCs (Supplemental Fig. S3C,D) and induced neuronal differentiation as described earlier. Wildtype iPSC-NE cells were competent to differentiate into

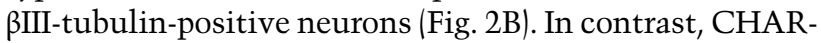
GE patient-derived iPSC-NE (CHARGE-NE) cells exhibited substantially reduced neuronal differentiation capacity and spontaneously gave rise to SMA-positive cells (Fig. 2B). These findings suggest that CHD7 insufficiency contributes to the loss of neurogenic competence that causes the ensuing derepression of a nonneural differentiation program. Consistent with this notion, when we overexpressed full-length CHD7 in CHARGE-NE cells, neuronal differentiation was restored, and conversion into smooth muscle cells was efficiently repressed (Fig. 2C). We next examined whether the altered differentiation capacity of CHARGE-NE cells was associated with the acquisition of a NC transcriptional signature, which occurs in CHD7 knockdown cells. By using the same sets of NPC- and NCC-enriched genes to compare correlations, we showed that the transcriptome profiles of CHARGE-NE cells were enriched for the NCC but not the NPC gene expression signature; conversely, wild-type NE cells corresponded to the NPC state (Fig. 2D).

Approximately $80 \%$ of CHARGE syndrome patients harbor either a nonsense $(44 \%)$ or frameshift mutation (34\%) (Janssen et al. 2012); if these mutated transcripts escape NMD, they can be translated into truncated CHD7 
A

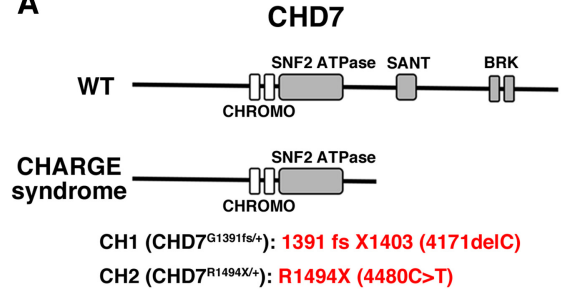

C
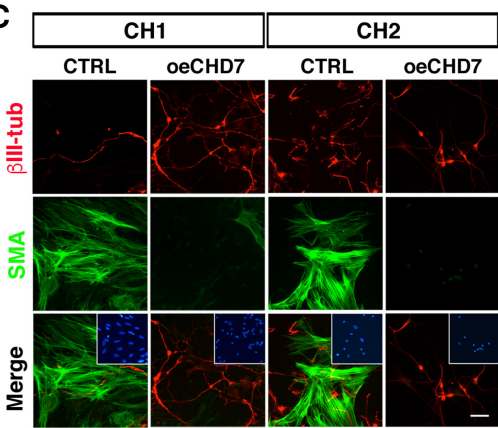

\section{D}
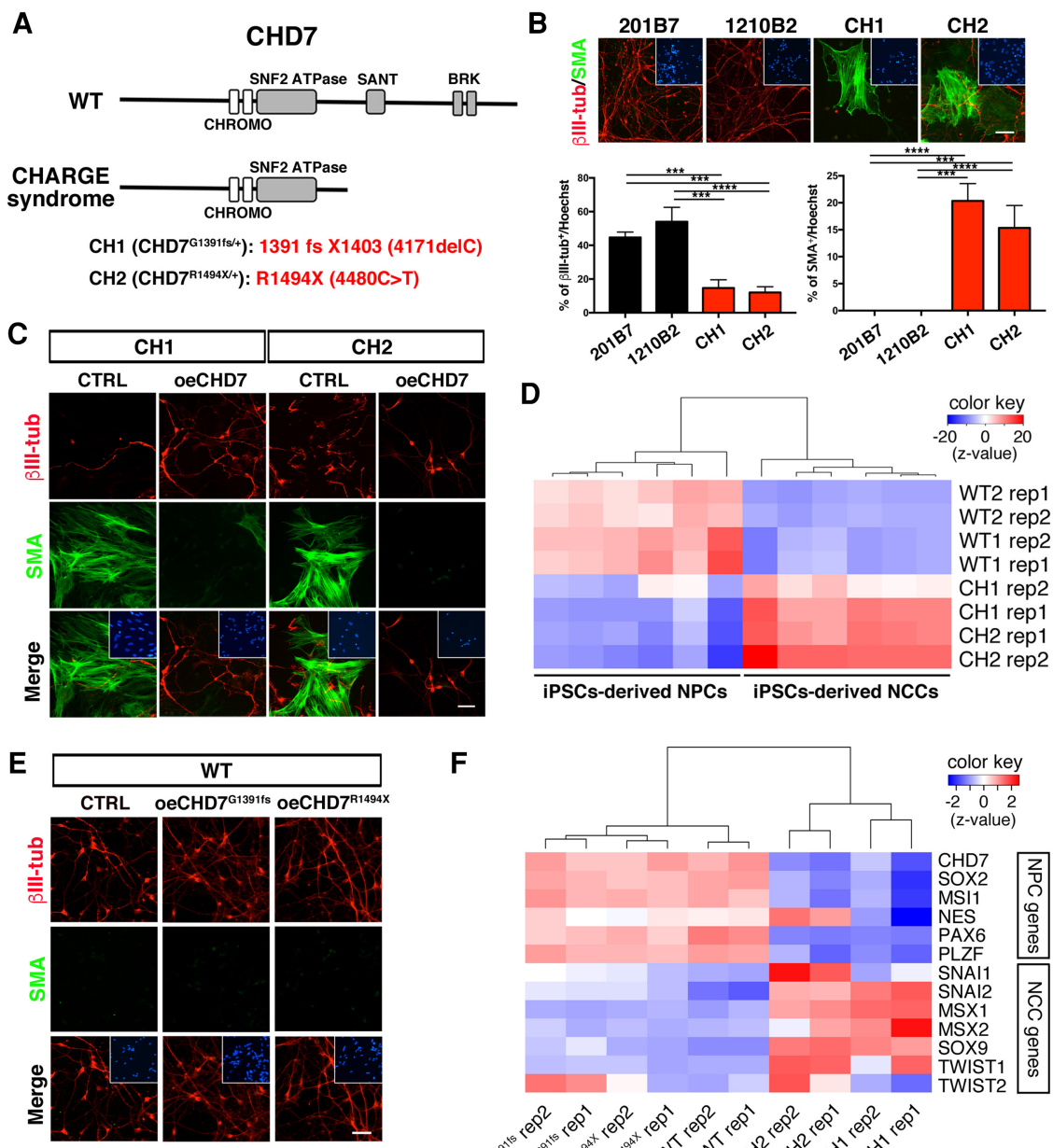

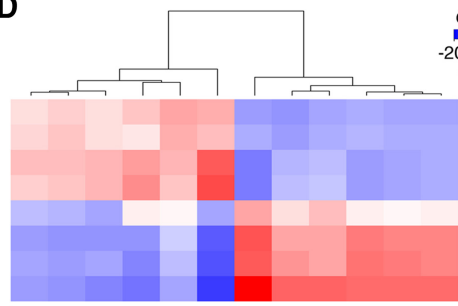

$\overline{\text { iPSCs-derived NPCs }} \overline{\text { iPSCs-derived NCCs }}$
$\mathrm{F}$

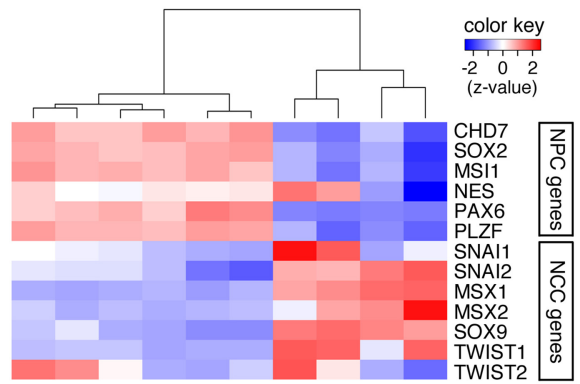

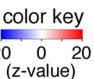

WT2 rep1 WT2 rep2 WT1 rep2 WT1 rep1 CH1 rep2 $\mathrm{CH} 1$ rep1 $\mathrm{CH} 2$ rep1 H2 rep2

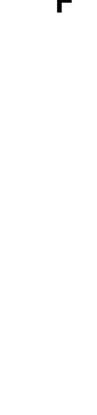

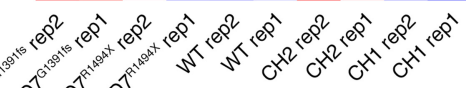

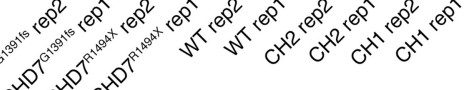

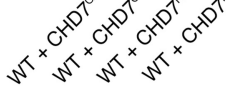

Figure 2. Gene expression programs dysregulated in $\mathrm{CHD} 7$ haploinsufficient iPSC-NE cells. (A) Illustration of frameshift and nonsense mutations in CHD7 harbored by the two CHARGE syndrome patients used in this study. ( $B$, top panel) Immunostaining of wild-type $\mathrm{NE}$ cells (201B7 and 1210B2) and CHARGE-NE cells ( $\mathrm{CH} 1$ and $\mathrm{CH} 2)$ after neuronal differentiation (at day 22) for ßIII-tubulin (red) and SMA (green). (Insets) Hoechst nuclear staining of each field. Bars, $50 \mu \mathrm{m}$. Quantification is shown in the bottom panel. $n=$ 3. Data are presented as the mean \pm SEM. ${ }^{(* * *)} P<0.001 ;\left({ }^{* * * *}\right) \quad P<0.0001$, one-way analysis of variance (ANOVA) with Bonferroni's post hoc test. $(C)$ Immunostaining of CHARGE-NE cells transfected with control vector (CTRL) or vector carrying fulllength wild-type CHD7 (oeCHD7) for $\beta$ IIItubulin and SMA after neuronal differentiation (at day 22). (Insets) Hoechst nuclear staining of each field. Bars, $50 \mu \mathrm{m} .(D)$ Heat map representation of the correlation of the gene expression of wild-type and CHARGE-NE cells with the gene expression of iPSC-derived NPC-enriched and iPSC-derived NCC-enriched genes. The color indicates the $z$-value for correlation significance. (E) Immunocytochemistry showing $\beta$ III-tubulin and SMA expression for AF22 cells carrying control vector and AF22 cells carrying mutant $\mathrm{CHD} 7$ proteins (CHD7 $7^{\mathrm{G} 1391 \mathrm{fs}}$ or $\mathrm{CHD} 7^{\mathrm{R} 1494 \mathrm{X}}$ ) after neuronal differentiation (at day 22). (Insets) Hoechst nuclear staining of each field. Bars, $50 \mu \mathrm{m}$. $(F)$ Heat map displaying the expression levels of six NPC-enriched genes and seven NCC-enriched genes in wild-type NE cells, NE cells expressing
up are listed. The color indicates the $z$-value mutant CHD7 proteins, and CHARGE-NE cells. (Right) Representative genes for each group are listed. The color indicates the $z$-value
for correlation significance.

protein. We asked whether $\mathrm{CHD} 7^{\mathrm{G} 1391 \mathrm{fs}}$ and $\mathrm{CHD} 7^{\mathrm{R} 1494 \mathrm{X}}$ could exert a dominant-negative effect on wild-type CHD7. We confirmed the expression of mutant CHD7 proteins in human embryonic kidney (HEK) 293T cells using automated Western blotting (Supplemental Fig. S3E). Next, we established NE cell lines stably expressing mutant CHD7 proteins and differentiated them into neurons. The expression of either $\mathrm{CHD} 7^{\mathrm{G} 1391 \mathrm{fs}}$ or $\mathrm{CHD} 7^{\mathrm{R} 1494 \mathrm{X}}$ did not cause aberrant differentiation capacity; both cell lines generated $\beta$ III-tubulin-positive neurons with efficiencies comparable with those of wild-type NE cells, and no smooth muscle cells were observed (Fig. 2E). To ascertain the molecular identities of the respective NE cell lines that we established, we performed microarray analysis to characterize the global transcriptome profiles of wildtype NE cells, NE cells overexpressing CHD7 ${ }^{\mathrm{G} 1391 \mathrm{fs}}$ or $\mathrm{CHD} 7^{\mathrm{R} 1494 \mathrm{X}}$, and CHARGE-NE cells. Our clustering analyses revealed that wild-type NE cells and NE cells overexpressing $\mathrm{CHD} 7^{\mathrm{G} 1391 \mathrm{fs}}$ or $\mathrm{CHD} 7^{\mathrm{R} 1494 \mathrm{X}}$ clustered together in a group that was clearly separated from CHARGE-NE cells (Fig. 2F). The expression of NPC-enriched genes, such as SOX2, MSI1, NES, PAX6, and PLZF, remained high in wild-type NE cells and NE cells overexpressing $\mathrm{CHD}^{\mathrm{G} 1391 \mathrm{fs}}$ or $\mathrm{CHD} 7^{\mathrm{R} 1494 \mathrm{X}}$. Conversely, CHARGE-NE cells were characterized by aberrant up-regulation of NCC-enriched genes, such as SNAI1/2, MSX1/2, SOX9, and TWIST1/2, concomitant with the down-regulation of $C H D 7$ (Fig. 2F). Such distinction, together with our earlier observation that forced expression of CHD7 rescued the aberrant phenotype in CHARGE-NE cells, thus suggests that reduced CHD7 expression causes global gene expression changes that underlie the pathological mechanisms of both CHD7 frameshift and nonsense mutations.

\section{CHD7 binds to the majority of SEs in NE cells}

To gain a better understanding of the molecular mechanisms by which CHD7 regulates NE cell identity, we 
performed ChIP-seq (Johnson et al. 2007) to identify genomic targets of CHD7 in NE cells. First, we generated ChIPseq data for CHD7 using two commercially available $\alpha$ CHD7 antibodies (CHD7 ChIP-seq) but observed an apparent lack of ChIP-seq density overall (Supplemental Fig. S4A). We reasoned that single fixation of cells with formaldehyde might be inefficient, especially when it has not been clarified whether CHD7 binds directly to DNA. We then generated another set of ChIP-seq data for $a-\mathrm{CHD} 7$ (CST) using dual cross-linking reagents formaldehyde and ethylene glycol bis (EGS; succinimidyl succinate) (Yu et al. 2015) and identified 22,939 binding sites in NE cells (Supplemental Fig. S4A). Although the dual crosslinking protocol significantly improved the immunoprecipitation efficiency of $\alpha$-CHD7 (CST), owing to its ability to capture indirect DNA-protein associations, it inevitably included false positive sites. To address this issue, we established two individual clones of NE cells (\#CB1 and \#F10) stably expressing a human influenza hemagglutinin (HA) tag integrated into the endogenous CHD7 locus using CRISPR-Cas9-mediated genome editing (Supplemental Fig. S5A-E; Cong et al. 2013; Doudna and Charpentier 2014; Hsu et al. 2014; Sander and Joung 2014; Savic et al. 2015) and generated alternative ChIP-seq sets using $\alpha$-HA (Supplemental Fig. S4B). Integration of a-CHD7 (CST)/ EGS and $\alpha$-HA ChIP-seq data sets identified 12,345 common binding sites, and 10,986 of these sites represented high-confidence CHD7-bound sites (Supplemental Fig. S4C; Supplemental Table S1). GO analyses of CHD7bound regions revealed the significant presence of GO terms related to neurulation, which includes neural tube formation, neural tube closure, and embryonic epithelial tube formation (Fig. 3A). This neurulation signature is strongly relevant to the hallmark features of CHARGE syndrome, given that the characteristic defects of this syndrome suggest dysfunctions in the neurulation process (Sanlaville and Verloes 2007). Genome distribution analysis showed that $11 \%$ of CHD7 occupancy was located proximal to transcription start sites, whereas $39 \%$ was located in intergenic regions (Fig. 3B). To gain further insights into the functional properties of $\mathrm{CHD} 7$, we generated chromatin landscapes of CHD7-bound regions, including H3K27ac, H3K4me1, H3K4me3, H3K9me3, H3K27me3, H3K36me3, and p300. Bioinformatics analyses revealed a striking overlap of regions bound by CHD7 with those of p300, H3K27ac, and H3K4me1, in which these marks are indicative of active enhancers (Fig. 3C; Creyghton et al. 2010). Conversely, CHD7 binding is most unlikely to occur within the promoter or an actively transcribed gene body region, as evidenced by the minimal or lack of correlation with H3K4me3 and H3K36me3 (Fig. $3 \mathrm{C})$. In addition, we observed a pronounced depletion of $\mathrm{H} 3 \mathrm{~K} 27 \mathrm{me} 3$ and $\mathrm{H} 3 \mathrm{~K} 9 \mathrm{me} 3$ repressive histone marks at CHD7-bound regions (Fig. 3C), indicating that CHD7 acts as an activator in NE cells. Through an overlay of CHD7-binding sites with genome-wide profiles of chromatin states in the neural progenitor lineage created by the Roadmap Epigenomics Consortium (http://www. roadmapepigenomics.org), we confirmed the predominant localization of $\mathrm{CHD} 7$ to enhancer elements; $25 \%$ of $\mathrm{CHD} 7$ binding occurred at enhancer elements, although enhancers constitute only $2 \%$ of the genome (Supplemental Fig. S4D).

A previous study had described Chd7 as one of the components enriched in SEs across the ESC genome (Hnisz et al. 2013). Given that SEs confer cellular identities (Whyte et al. 2013; Adam et al. 2015), we hypothesized that the maintenance of NE cell identity involves the binding of CHD7 to SEs. We first delineated typical enhancers (TEs) and SEs in NE cells based on H3K27ac abundance using the ROSE algorithm and identified 1012 SEs (Fig. 3D; Supplemental Table S2; Whyte et al. 2013). Although SEs constitute only $5 \%$ of active enhancers, we found that nearly all H3K27ac-defined SEs $(92 \%)$ were CHD7-bound (Fig. 3E), suggesting that CHD7 is preferentially localized to SEs in human NE cells. Notably, SEs tend to be found proximal to genes encoding key regulators of neural development and neurogenesis, such as ZIC4, BRN2, SOX21, and SOX1 (Fig. 3D). Consistently, $\mathrm{GO}$ analysis of SE-associated genes revealed neural tube development as the enriched GO term (Supplemental Fig. S4E), indicating that CHD7 localizes at SEs of NE cells to regulate neural/NE fate.

\section{CHD7 activates lineage-specific enhancers in human NE cells}

To determine the enhancer properties of CHD7-bound distal regions, we evaluated these regions using the VISTA Enhancer Browser (Visel et al. 2007), a database of tissuespecific human enhancers with validated activity in mice. CHD7-binding sites were most enriched for CNS active enhancer elements (Fig. 3F), including the neural tube, midbrain, hindbrain, and forebrain. As a case in point, we found that $\mathrm{CHD} 7$ binding at SE-associated genes in NE cells, including GLI3 and ZIC1/4 loci, coincided with the presence of annotated enhancers that exhibit strong activity in the brain and neural tube (Fig. 3G). Conversely, annotated enhancers without CHD7 either showed strong expression in limbs or were functionally inactive (Fig. 3G). The identification of CNS-specific $\mathrm{CHD} 7$-enriched enhancers suggests that $\mathrm{CHD} 7$ regulates CNS specificity of its corresponding genes and, more importantly, indicates a role for CHD7 in CNS lineage determination.

\section{CHD7 activates lineage-specific enhancers in NE cells}

We found that CHD7 is selectively associated with CNSspecific enhancers, but little is known about CHD7-mediated enhancer regulation. In light of the notion that enhancer activity is correlated with the abundance of H3K27ac, we evaluated whether the reduction of $\mathrm{CHD} 7$ contributes directly to altered H3K27ac enrichment at CHD7-binding sites across the genome in CHD7 knockdown and CHARGE-NE cells. Compared with control knockdown or wild-type NE cells, CHD7 knockdown NE cells and CHARGE-NE cells displayed an average decrease in $\mathrm{H} 3 \mathrm{~K} 27 \mathrm{ac}$ at $\mathrm{CHD} 7-$ bound regions (Fig. 4A). We next determined whether H3K27ac surrounding SE 
A GO Biological Process (CHD7 enriched regions)

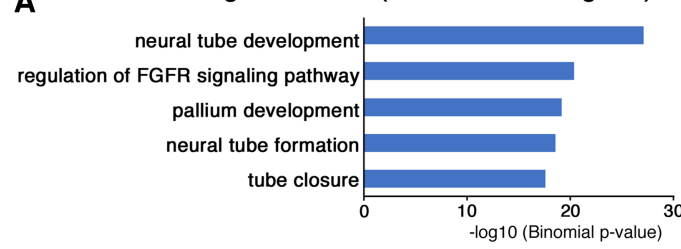

B

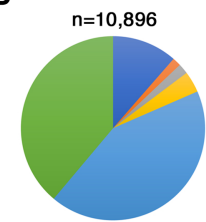

Dromoter (11.4\%)

5' UTR (1.5\%)

3' UTR (1.8\%)

Exonic $(3.7 \%)$

Intronic (42.7\%)

Intergenic (38.9\%)
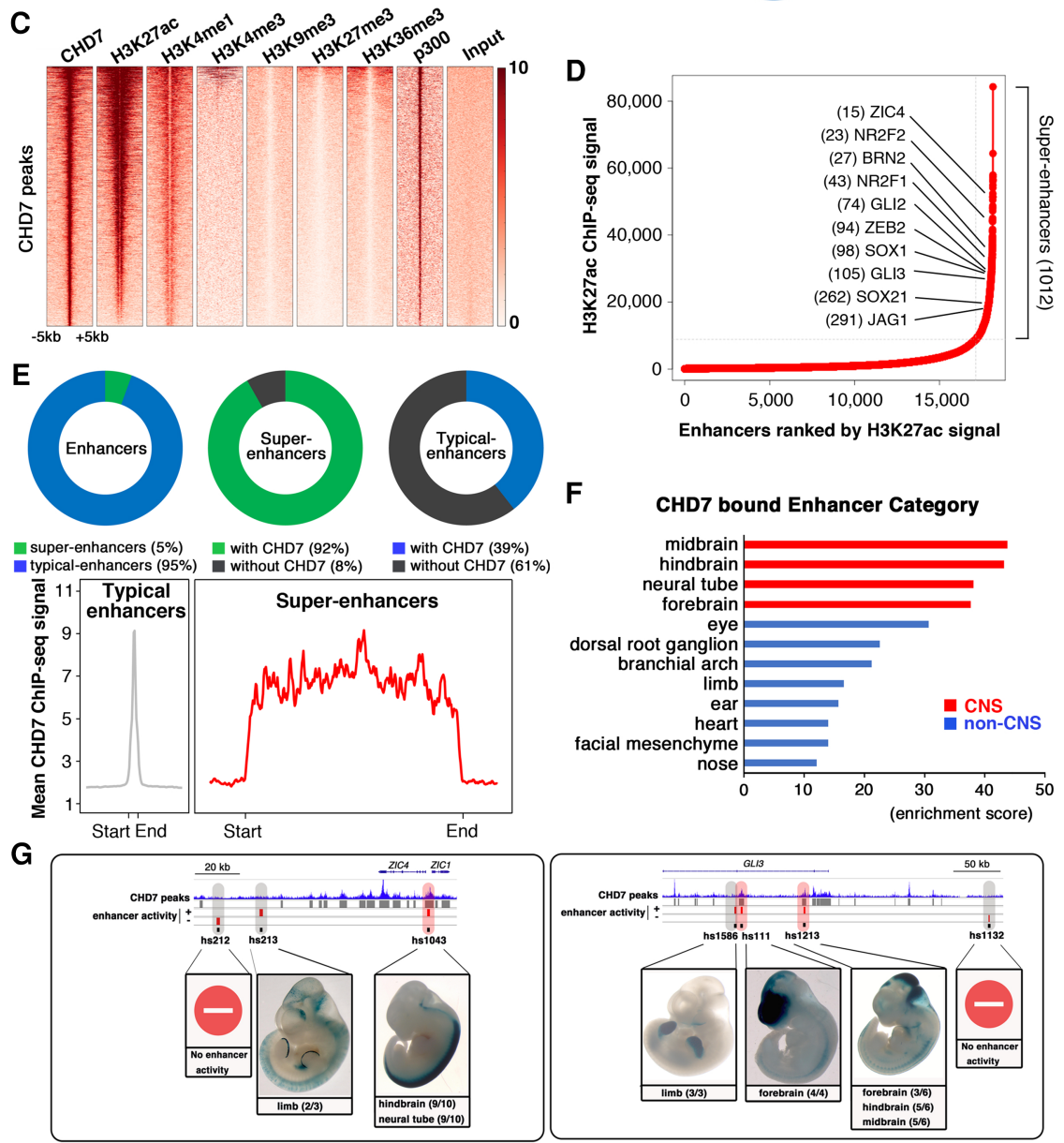

Figure 3. CHD7 selectively binds to SEs and CNS-specific enhancers in NE cells. (A) GO analysis for biological processes associated with $\mathrm{CHD} 7-$ bound regions. $(B) \mathrm{Ge}$ nomic distribution of CHD7-bound regions in NE cells. $(C)$ Heat map analyses of ChIPseq signals of CHD7 and selected histone modifications in NE cells. All ChIP-seq signals are displayed from $\pm 5 \mathrm{~kb}$ surrounding the center of each annotated CHD7 peak. Each CHD7-binding site is represented as a single horizontal line (red) centered on the peak summit. (D) Distribution of H3K27ac ChIP-seq density at enhancers plotted in increasing order based on inputnormalized H3K27ac ChIP-seq signal. A population of enhancers that appears above the inflection point of the curve is considered SEs. The respective ranks of SEs and their associated genes are shown. $(E$, top left) Distribution of typical enhancers (TEs) and SEs in NE cells. Distribution of CHD7 binding that occurred at SEs (top middle) and TEs (top right). Metagene representations of the mean ChIP-seq signal for CHD7 across TEs and SE domains are shown in the bottom panel. $(F)$ Functional annotation of genomic regions bound by CHD7 intersected with enhancer regions validated in the VISTA Enhancer Browser database. Bar plot showing enrichment of CHD7 occupancy across 12 different tissues. $(G)$ Snapshots showing combined tracks of CHD7 peaks (gray bars; extracted from $a$-HA ChIP-seq data) and VISTA-validated enhancer regions (red bars) near ZIC1/4 (left) and GLI3 (right). Shown below the tracks are screenshots of tissue-specific activities of the enhancers located proximal to ZIC1/4 and GLI3 tested in a lacZ reporter transgenic mouse assay and extracted from the VISTA Enhancer Browser database. regions was dependent on CHD7 abundance. Remarkably, we detected lower accumulation of H3K27ac in CHD7 haploinsufficiency than in wild type, consistent with that of CHD7 knockdown (Fig. 4B). Furthermore, we found that $30 \%$ of SE-associated genes were down-regulated in both CHD7 knockdown and CHARGE-NE cells (but not of those up-regulated; $<5 \%$ ) (Fig. 4C; Supplemental Table S3), establishing a role for CHD7 in regulating the activation of cell type-specific SEs and thus cell type-specific gene expression. We further analyzed whether CHD7 also modulates H3K27ac enrichment at CNS-specific enhancers identified using VISTA Enhancer Browser. We observed a decreased $\mathrm{H} 3 \mathrm{~K} 27 \mathrm{ac}$ signal at CNS-specific enhancers of CHD7 knockdown cells, albeit to a lower degree than that of CHARGE-NE cells (Fig. 4D). These results indicate a role for CNS-specific CHD7-enriched enhancer activity in the pathogenesis of CHARGE syndrome. To support the above findings, we categorized dysregulated H3K27ac-occupied regions in CHD7 knock- down and CHARGE-NE cells based on the tissue-specific enhancer activity of the VISTA Enhancer Browser. The majority of CHD7-bound enhancers had a reduced H3K27ac signal in both CHARGE-NE and CHD7 knockdown NE cells (Fig. 4E). Among these enhancers, we observed a selective enrichment of the CNS-specific one compared with the non-CNS one. Furthermore, such enrichment was highly dependent on CHD7 occupancy, as decreased $\mathrm{H} 3 \mathrm{~K} 27 \mathrm{ac}$ regions that were not occupied by CHD7 were evenly distributed across different tissue-specific enhancers (Fig. 4E). Nevertheless, non-CNS enhancers were overrepresented among CHD7-independent increased $\mathrm{H} 3 \mathrm{~K} 27 \mathrm{ac}$ regions, indicating that $\mathrm{CHD} 7$ is not directly responsible for the activation of a non-CNS fate program (Fig. 4E). Taken together, our findings suggest that CHD7 is responsible for maintaining H3K27ac levels and tissue-specific enhancer activity; however, reduced expression of CHD7 in NE cells is insufficient to preserve this activation, ultimately leading to the disruption of 
Chai et al.
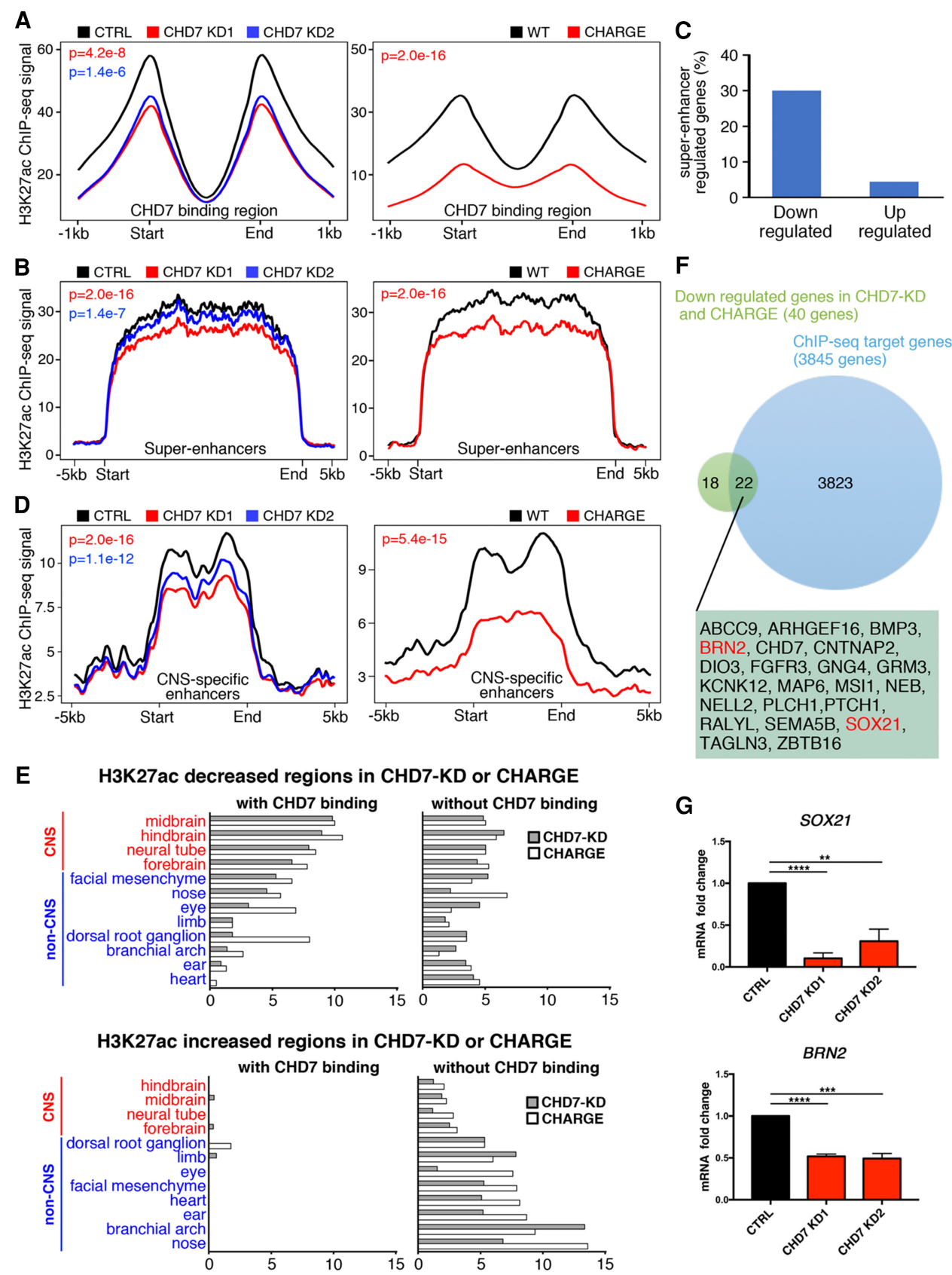

Figure 4. Epigenetic dysregulation is directly associated with CHD7 haploinsufficiency. (A, left panel) Density plots of mean H3K27ac ChIP-seq signals within $\pm 1 \mathrm{~kb}$ of CHD7 peak summits in control and CHD7 knockdown NE cells. (Right panel) Density plots of mean H3K27ac ChIP-seq signals within $\pm 1 \mathrm{~kb}$ of CHD7 peak summits in wild-type and CHARGE-NE cells. (B, left panel) Density plots of mean H3K27ac ChIP-seq signals encompassing SE domains in control and CHD7 knockdown NE cells. (Right panel) Density plots of mean H3K27ac ChIP-seq signals encompassing SE domains in wild-type and CHARGE-NE cells. (C) Bar plot showing the percentage of SE-associated genes, which are commonly down-regulated or up-regulated in CHD7 knockdown and CHARGE-NE cells. (D, left panel) Density plots of mean H3K27ac ChIP-seq signals at CNS-specific enhancers in control and CHD7 knockdown NE cells. (Right panel) Density plots of mean H3K27ac ChIP-seq signals at CNS-specific enhancers in wild-type and CHARGE-NE cells. (E) Common CHD7-bound regions with decreased/increased H3K27ac levels identified in CHD7 knockdown and CHARGE-NE cells were intersected with enhancer regions validated in the VISTA Enhancer Browser database and classified based on tissue-specific activity. These regions were further classified as with or without CHD7 binding. $(F)$ Venn diagram showing the overlap between CHD7 genomic targets (3845 genes) and commonly down-regulated targets in CHD7 knockdown and CHARGE-NE cells (40 genes). Twenty-two genes were identified as the cognate targets of CHD7. (G) qRT-PCR validation of SOX21 and BRN2 in control and CHD7 knockdown samples. $n=3$. Data are presented as the mean \pm SEM. $\left(^{(*)} P<0.01 ;\left({ }^{* * *}\right) P<0.001 ;\left({ }^{* * * *}\right) P<0.0001\right.$, two-tailed unpaired Student's $t$-test. 
cell type-specific gene expression and the CNS lineage program.

\section{CHD7-driven regulatory program in CHARGE pathogenesis}

Having identified a role for CHD7 in controlling NE cell identity and CNS lineage determination, we next sought to identify CHD7-driven downstream effectors responsible for this pathway. We overlaid the gene list obtained from ChIP-seq (Supplemental Table S4) with the list of down-regulated genes identified from the global gene expression profiles of control versus CHD7 knockdown and CHARGE-NE cells (Supplemental Table S3) and identified 22 genuine candidates (Fig. 4F). We focused on down-regulated genes, given the association of CHD7 with active H3K27ac marks, an indication that CHD7 functions predominantly as a transcriptional activator. Two candidates, SOX21 and BRN2, were of particular interest, considering their roles in neurogenesis (Sandberg et al. 2005; Vierbuchen et al. 2010). To determine whether CHD7 directly activates SOX21 and BRN2 in NE cells, we examined the expression of SOX21 and BRN2 and found that the expression of these genes was reduced in $\mathrm{CHD} 7$ knockdown NE cells (Fig. 4G). In addition, we found that decreased SOX21 and BRN2 expression was accompanied by visible reductions in H3K27ac enrichment at CHD7 peaks proximal to SOX21 and BRN2 (Fig. 5A,B), further strengthening our conclusion that $\mathrm{CHD} 7$ epigenetically regulates its target genes. To further validate the reduction in $\mathrm{H} 3 \mathrm{~K} 27 \mathrm{ac}$ levels around these regions, we examined the enhancer activities of several CHD7bound enhancer regions surrounding SOX21 and BRN2; we refer to these regions as R1-R4 (Fig. 5C,D; Supplemental Table S5). A search of the VISTA Enhancer Browser database revealed that three regions-R1 and R3 of SOX21 and R1 of BRN2-are functionally validated enhancers with activities enriched in the CNS (Fig. 5C,D). The remaining regions are putative enhancers identified in this study. We found that five of eight regions tested were active in reporter assays (Supplemental Fig. S6A). Furthermore, the activities of four out of five active reporters (two per candidate gene) were clearly reduced in the presence of CHD7 shRNA (Fig. 5C,D), suggesting that CHD7 regulates the gene expression of SOX21 and BRN2 through enhancer regions. Earlier, we showed that AF22 cells expressing $\mathrm{CHD}^{\mathrm{G} 1391 \mathrm{fs}}$ or $\mathrm{CHD}^{\mathrm{R} 1494 \mathrm{X}}$ exhibited no significant alterations in their differentiation ability, and no dominant-negative effects were observed. Thus, we sought to further confirm that these mutants do not functionally inhibit CHD7-mediated enhancer activation. We examined the enhancer activities of two regions-namely, SOX21-R1 and BRN2-R3-in NE cells expressing mutant $\mathrm{CHD} 7$ proteins and found that the inhibitory effects, if any, of mutant CHD7 are likely marginal (Supplemental Fig. S6B). These findings thus revealed the exquisite dosage requirement for $\mathrm{CHD} 7$ in preserving its activator function in gene regulation.

To further confirm that CHD7 localization to these regions is NE-specific, we compared CHD7 binding proxi- mal to SOX21 and BRN2 with that in iPSCs and NCCs. We found distinguishable CHD7 peaks at genomic regions surrounding SOX21 and BRN2, most strongly in the NE state compared with that in iPSC and NCC states (Fig. 5E). Attesting to its cell type-specific binding pattern, CHD7 occupancy was selectively enriched in genomic regions proximal to OCT4 and NANOG in the iPSC state, whereas distinct $\mathrm{CHD} 7$ peaks were detected proximal to SOX9 and SNAI1 in the NCC state (Fig. 5E). These results support a cell type-specific regulatory role for CHD7.

To further understand the role of SOX21 and BRN2 in NE cells, we performed loss-of-function and rescue experiments and found that the neuronal differentiation ability of NEs was adversely affected by knockdown of BRN2 (Fig. 6A) and, to a much lesser extent, knockdown of $S O X 21$ (data not shown). In either case, we observed only a few SMA-positive cells, and the majority of the cell population was not $\beta$ III-tubulin- or SMA-positive (Fig. 6A). Overexpression of BRN2 in parallel with CHD7 knockdown rescued the aberrant phenotype, as evidenced by the significantly enhanced capacity of these cells for differentiation into $\beta I I I-$ tubulin-positive neurons and the complete absence of SMA-positive cells (Fig. 6B). Overexpression of SOX21 in CHD7 knockdown NE cells resulted in a partial increase in the number of $\beta$ III-tubulin-positive neurons while moderately suppressing the generation of SMA-positive cells (Fig. 6B). We next asked whether overexpression of BRN2 in CHARGE-NE cells could restore neuronal differentiation capacity. As a result, we observed an increase in the population of $\beta$ III-tubulin-positive neurons ( 30\%) in BRN2-overexpressing CHARGE-NE cells compared with that in cells transduced with a control vector; however, these neurons appeared immature, as indicated by their relatively short processes (Fig. 6C). Nevertheless, the expression of BRN2 inhibited the differentiation of SMA-positive cells (Fig. 6C), suggesting a partial restoration of neural identity and neurogenic competence in CHARGE-NE cells. Although BRN2 exerts a stronger neurogenic effect than SOX21, our data further confirm the notion that SOX21 and BRN2 play a critical role in preserving the neurogenic potential of NE cells. Altogether, our findings indicate that, through modulation of SE activity, CHD7, SOX21, and BRN2 coordinately orchestrate the NE-specific gene expression program during NE-NC lineage commitment.

\section{Discussion}

In this study, we found that CHD7, the causative gene in CHARGE syndrome, is a master regulator of maintenance of the lineage-specific epigenome and cell type-specific gene expression that is integral to NE cell fate and CNS lineage commitment. An abundance of $\mathrm{CHD} 7$ is required to preserve the activation of cell type-specific enhancers for CNS lineage, maintaining the identity of CNS cell types irrespective of cellular state. Down-regulation of CHD7 in NE cells caused a fate switch from NE to NC- 
Chai et al.
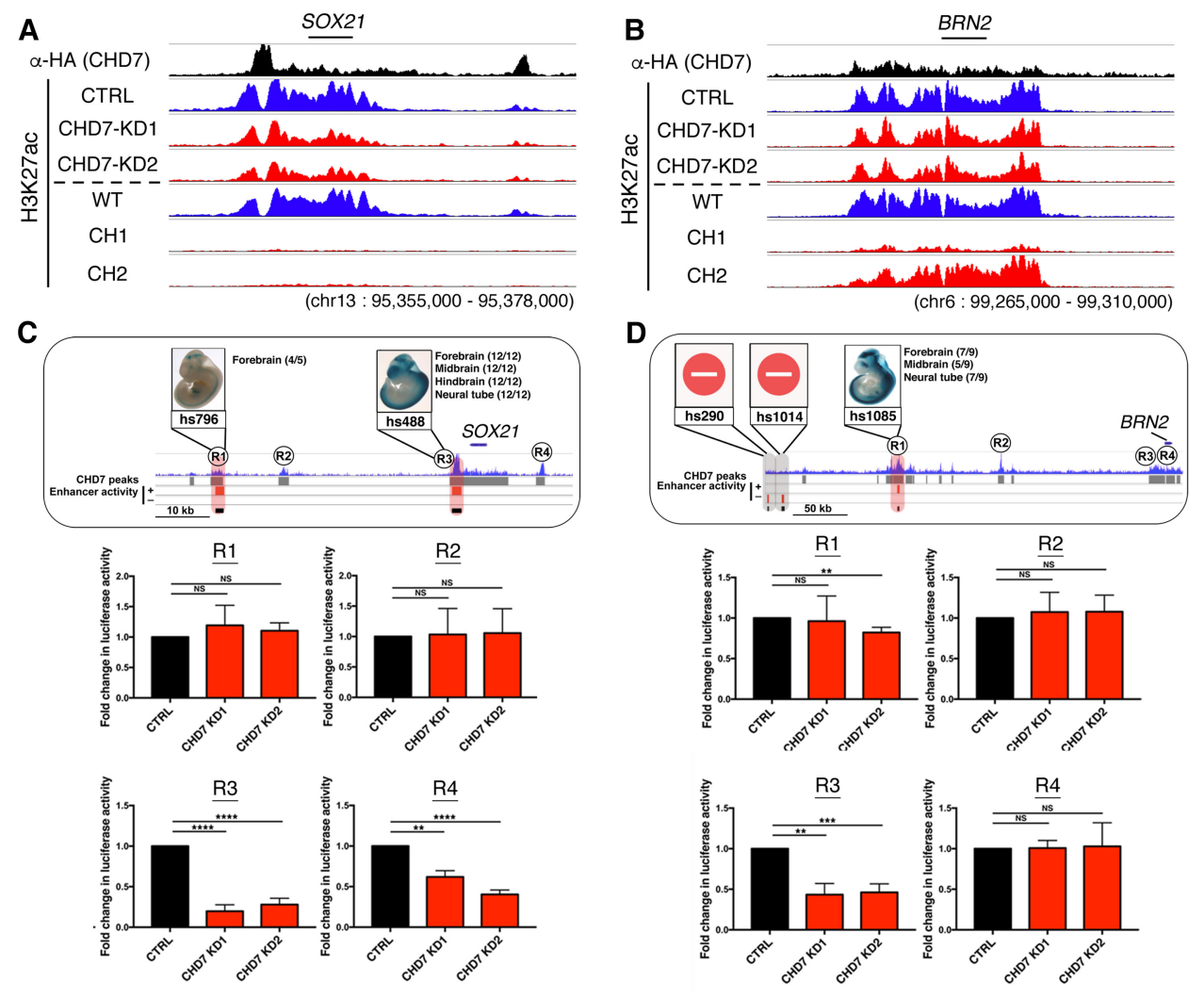

$\mathbf{E}$
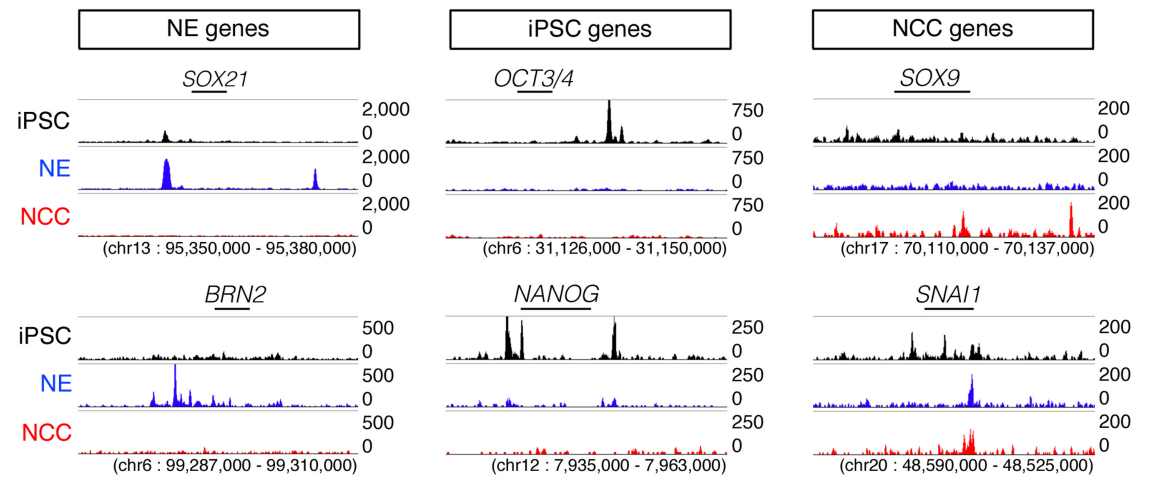

Figure 5. CHD7 regulates SOX21 and BRN2 expression by direct activation of SEs. $(A, B)$ CHD7 occupancy at the $S O X 21(A)$ and $B R N 2$ (B) genomic loci together with the enrichment of H3K27ac at these loci in control knockdown and wild-type NE cells versus CHD7 knockdown NE cells and CHARGE-NE cells. The ChIP-seq signal obtained using $\alpha$-HA (HA knock-in into the CHD7 locus) was used to depict CHD7 occupancy at these regions. $(C, D)$ Representative tracks showing CHD7 peaks (gray bars) and VISTA-validated enhancer regions (red bars) around SOX21 $(C)$ and BRN2 (D). Enhancer activities of distal genomic regions proximal to SOX21 (hs488 [R3] and hs796 [R1]) and BRN2 (hs290, hs1014, and hs1085 [R1]) were validated using a lacZ reporter transgenic mouse assay and are available in the VISTA Enhancer Browser database. CHD7-bound regions with enhancer activities in the CNS are shaded in red (hs796 and hs488 for SOX21 and hs1085 for BRN2). The regions with no recorded enhancer activity are shaded in gray (hs290 and hs1014). (Bottom panel) A luciferase reporter assay was performed in control and CHD7 knockdown NE cells to determine the activity of CHD7-bound enhancers near SOX21 and $B R N 2$. A Renilla reporter was included for normalization (F/R ratio). Corresponding regions examined are shown in the top panel. Data are presented as the mean \pm SEM. $\left(^{* *}\right) P<0.01 ;\left(^{* * *}\right) P<0.001 ;\left({ }^{* * * *}\right) P<0.0001$, two-tailed unpaired Student's $t$-test. $(E)$ ChIP-seq signals for CHD7 at genomic loci specific to human NE cells (SOX21 and BRN2) (left panel), human iPSCs (OCT4 and NANOG) (middle panel), and human NCCs (SOX9 and SNAI1) (right panel) in each of these cell lines. The ChIP-seq signal for CHD7 (a-CHD7 [CST]/ EGS) was used to depict CHD7 occupancy.

like cells by a reduction in $\mathrm{H} 3 \mathrm{~K} 27 \mathrm{ac}$ abundance at CNSspecific enhancers and, conversely, an increase in $\mathrm{H} 3 \mathrm{~K} 27 \mathrm{ac}$ abundance at non-CNS enhancers, which fur- ther instruct an abrupt change in the cell type-specific gene expression program. Finally, we showed that SOX21 and BRN2 were the downstream effectors of 

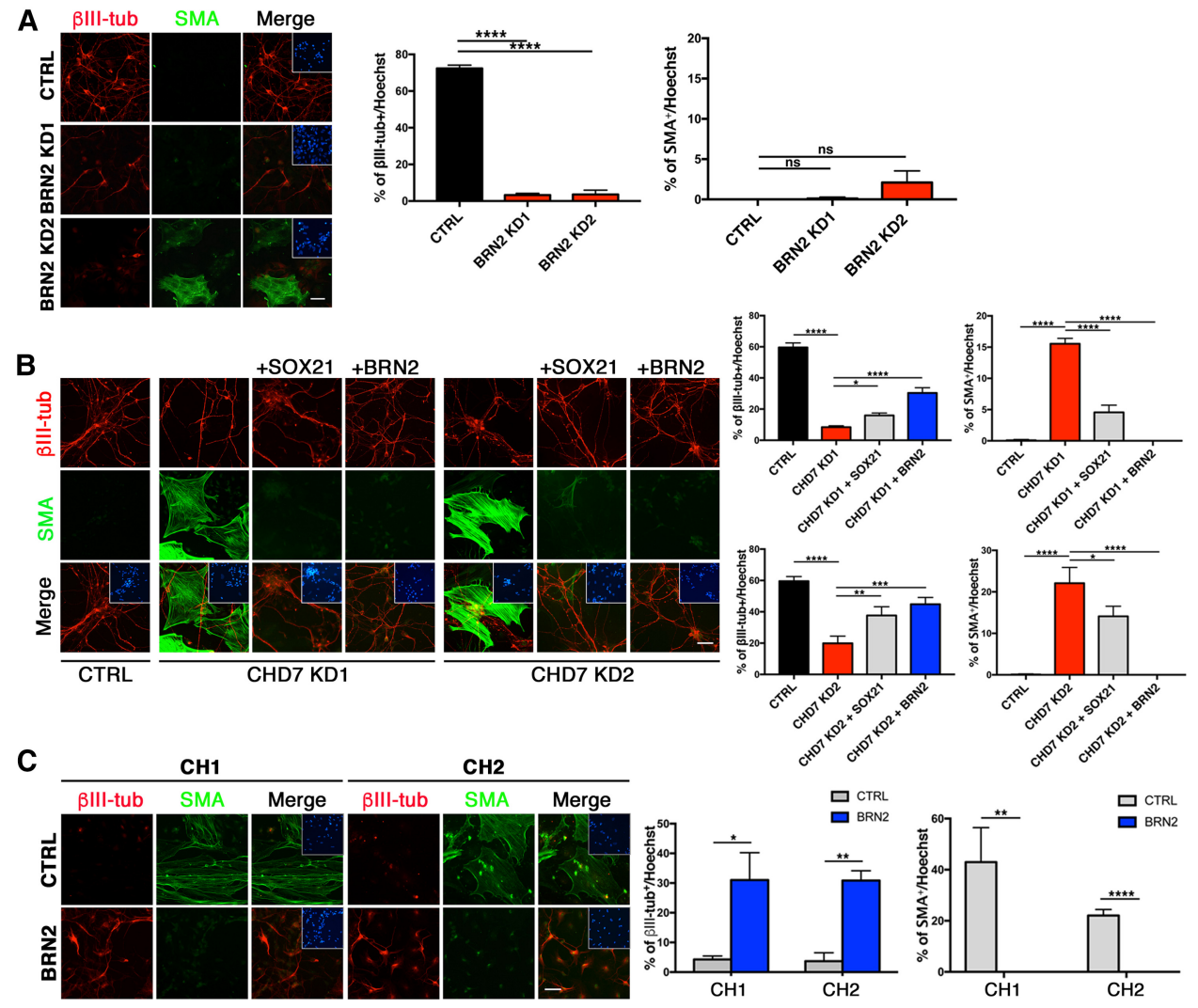

Figure 6. Overexpression of BRN2 alleviates disease manifestation in CHARGE-NE cells. (A, left panel) Immunostaining of control and BRN2 knockdown cells after neuronal differentiation (at day 22) for $\beta$ III-tubulin and SMA. (Insets) Hoechst nuclear staining of each field. Bars, $50 \mu \mathrm{m}$. Quantification is shown in the right panel. $n=3$. Data are presented as the mean \pm SEM. $\left({ }^{* * * *}\right) P<0.0001$, two-tailed unpaired Student's $t$-test. ( $B$, left panel) Immunostaining for $\beta I I I-t u b u l i n(r e d)$ and SMA (green) in differentiated control, CHD7 knockdown, and SOX21- or BRN2-overexpressing CHD7 knockdown NE cells. (Insets) Hoechst nuclear staining of each field. Quantification of the number of $\beta$ III-tubulin- and SMA-expressing cells under each condition is shown in the right panel. $n=3$. Data are presented as the mean \pm SEM. $(*)$ $\left.\left.P<0.05 ;\left(^{* *}\right) P<0.01 ;{ }^{* * *}\right) P<0.001 ;{ }^{* * * *}\right) P<0.0001$, two-tailed unpaired Student's $t$-test. $(C$, left panel) Immunostaining for $\beta I I I-t u b u l i n$ (red) and SMA (green) in differentiated patient CHARGE-NE cells transduced with or without BRN2. (Insets) Hoechst nuclear staining of each field. The number of $\beta$ III-tubulin- and SMA-expressing cells in each condition is shown in the right panel. $n=3$. Data are presented as the mean \pm SEM. $\left(^{*}\right) P<0.05 ;\left(^{* *}\right) P<0.01 ;\left(^{* * * *}\right) P<0.0001$, one-way ANOVA with Bonferroni's post hoc test.

CHD7 function in controlling neurogenic competence. Most importantly, by using CHARGE syndrome patientderived NE cells, our proposed mechanism has substantive implications in the pathogenesis of CHARGE syndrome.

Single-cell lineage analysis demonstrates that a single $\mathrm{NE}$ cell in vivo can differentiate into derivatives of either the CNS or NC (Bronner-Fraser and Fraser 1988, 1989; Frank and Sanes 1991; Selleck and Bronner-Fraser 1995; Brown and Storey 2000). A recent study further demonstrated that the conversion of mouse cortical neural stem cells at E14.5 to NCCs was possible by activating Sox9 while repressing Sox2 (Remboutsika et al. 2011). These studies indicate that the CNS is not fully segregated from the NC even at mid-stage embryonic development; thus, the CNS must have mechanisms in place to maintain CNS lineage identity. Here, we provided three independent lines of evidence to support the notion that CHD7 maintains the current cell state and CNS lineage identity in NE cells. First, $>50 \%$ of CHD7 knock- down NE cells lost the expression of NE identity markers, including SOX1 and DACH1 (Fig. 1D). Second, morphological changes from rosette-like patterns to mesenchymal-like cell patterns were observed as early as day 5 after lentiviral-mediated CHD7 knockdown, and ectopic up-regulation of NC master regulators SOX9 and SNAI2 was observed beginning at day 8 (Supplemental Fig. S1D). Furthermore, global transcriptome profiles of CHD7 knockdown NE cells revealed the manifestation of a NC-specific gene expression program (Fig. 1G). Third, the neuronal differentiation rate decreased by $>50 \%$ for CHD7 knockdown NE cells, which instead differentiated into smooth muscle cells (Fig. 1E). In addition, we show that both in vitro and in vivo, NE cells express a higher level of CHD7 than NCCs (Fig. 1B,C), suggesting that $\mathrm{CHD} 7$ may act as a segregation factor for the CNS and NC.

Mesenchymal stem cells (MSCs)/stromal cells share developmental similarities and differentiation potential with NCCs, consistent with the views that MSCs 
partially originate from NCCs (Takashima et al. 2007; Nagoshi et al. 2008; Fukuta et al. 2014). For instance, the craniofacial mesenchyme and a subpopulation of bone marrow MSCs developmentally originate from NCCs (Chai et al. 2000; Hagiwara et al. 2014; Isern et al. 2014; Wiszniak et al. 2015). Moreover, the mesoderm is a major source of the MSCs that give rise to skeletal and connective tissues (Olsen et al. 2000). We found that the transcriptome profiles of $\mathrm{CHD} 7$ knockdown cells are equally consistent with MSCs, as determined by singlecell RNA-seq analysis (Supplemental Fig. S2). However, our present work was unable to distinguish the exact origin of these cells, specifically whether they are derived from the NC, neuroectoderm, or mesoderm. In this context, a previous study showed that Sox $1^{+} \mathrm{NE}$ cells give rise to MSCs through a NC intermediate stage; however, this process accounts for merely $1.3 \%$ of the total MSC population (Takashima et al. 2007), suggesting that direct conversion from neuroepithelium to mesoderm is rather unlikely. Thus, further experiments are needed to determine the role of $\mathrm{CHD} 7$ in mesodermal lineage commitment.

Our study reveals a novel function for $\mathrm{CHD} 7$ in activating lineage-specific enhancers in NE cells. CHD7 binds preferentially to distal regulatory elements, particularly SEs, in human ESCs and mouse cerebellar granule neuron progenitors (Hnisz et al. 2013; Feng et al. 2017). Although SEs control cell identity, previous studies did not show disruption of CHD7 and, presumably, binding of CHD7 to SEs, resulting in the loss of cell identity. Here, we present several lines of evidence that $\mathrm{CHD} 7$ regulates cell and lineage identities through maintenance of the active enhancer repertoire and a cell type-specific gene expression program. We observed a high level of CHD7 binding at SEs, in which CHD7-associated genes are master regulators of neural development and neurogenesis (Fig. 3D,E; Supplemental Table S2). Knockdown of CHD7 in NE cells correspondingly altered H3K27ac abundance surrounding SE regions (Fig. 4B), consistent with the down-regulation of $30 \%$ of SE-associated genes in CHD7 knockdown cells (Fig. 4C) and disablement of the NE-specific gene expression program (Fig. 1G). We found that CHD7-bound distal regions are most enriched for CNS-specific enhancers (Fig. 3F,G). In CHD7 knockdown cells, the average $\mathrm{H} 3 \mathrm{~K} 27 \mathrm{ac}$ signal at CNS-specific enhancers but not nonCNS enhancers was decreased (Fig. 4D,E). Our data show that CHD7 is directly responsible for enhancer activity, but our work is insufficient to address why NE cells undergo a fate switch to NC-like cells in the absence of CHD7, especially in light of our findings that non-CNS enhancers were overrepresented among CHD7-independent increases in $\mathrm{H} 3 \mathrm{~K} 27 \mathrm{ac}$ regions upon CHD7 abrogation (Fig. 4E).

We identified SOX21 and BRN2 as primary targets of CHD7 in NE cells (Fig. 4F,G). At CHD7 peaks proximal to SOX21 and BRN2, H3K27ac levels were reduced upon CHD7 knockdown (Fig. 5A,B). The enhancer activities of these regions, as measured by a luciferase reporter assay, were markedly reduced in the presence of $\mathrm{CHD} 7$ shRNAs (Fig. 5C,D). Knockdown of BRN2 in NE cells ad- versely affected neuronal differentiation ability and milder defects with knockdown of SOX21, but no spontaneous smooth muscle differentiation was observed (Fig. 6A). These results might be explained by the critical role that SOX21 and BRN2 play in conferring neurogenic competence to NE cells; however, they play a much less substantial role in blocking alternative lineages. Nevertheless, neuronal differentiation ability was restored and smooth muscle differentiation was repressed in CHD7 knockdown cells overexpressing BRN2 or SOX21 (Fig. 6B). The finding that the CHD7-driven regulatory program is essential for in vitro NE rosette cultures is of potential relevance in the development of three-dimensional organoid-based functional modeling of human brain development, given that the neuroepithelium is the fundamental building block of brain organoids.

Most importantly, our work shows that these novel functions of CHD7 in NE cells may underlie neurodevelopmental defects, particularly in the CNSs of patients with CHARGE syndrome caused by frameshift or nonsense mutations of CHD7. We found that CHARGE-NE cells exhibited altered differentiation capacity similar to that of CHD7 knockdown cells (Fig. 2B). In contrast, overexpression of $\mathrm{CHD} 7^{\mathrm{G} 1391 \mathrm{fs}}$ or $\mathrm{CHD} 7^{\mathrm{R} 1494 \mathrm{X}}$ in NE cells has no discernible phenotypes without any dominant-negative effects (Fig. 2E). Exogenous expression of $\mathrm{CHD} 7$ in CHARGE-NE cells enhanced neuronal differentiation capacity and inhibited smooth muscle cell differentiation (Fig. 2C). Previous studies on lineage maintenance in the immune cells showed that the binding characteristic of a single TF to genomic regions relies on its nuclear concentration (Heinz et al. 2010). When a TF is expressed at lower levels, this TF relies strongly on its cognate partner TFs to bind to many genomic sites, thus establishing a different set of active enhancers than that established by a TF expressed at high levels. Consistently, our work shows that the level of CHD7 expression in CHARGE-NE cells is inadequate to maintain the CNS lineage-specific epigenome (Fig. 4), ultimately leading to the loss of the NE-specific gene expression program (Fig. 2D,F). This finding indicates an absolute requirement for the continuous presence of CHD7 in CNS development.

In conclusion, our study uncovers a previously unappreciated role for $\mathrm{CHD} 7$ in CNS lineage maintenance. By using iPSC-NE cell-based disease modeling, our study sheds light on the molecular link between CNS anomalies and craniofacial malformations in CHARGE syndrome patients. Our findings suggest that collapse of a cell typespecific gene expression program in the NE progenitor population that causes the ensuing lineage switch to multipotent NC-like cells is sufficient to affect a wide range of neural and NC derivatives throughout human fetal development. Thus, our study provides insights into the longstanding question regarding the causes of multiple anomalies in CHARGE syndrome patients. This study also highlights the feasibility of using human iPSC-based research to improve the understanding of human neurodevelopment and neurodevelopmental disorders, bringing us another step closer to decoding the complexity of the human CNS. 
Materials and methods

Cell culture

The human iPSC lines derived from healthy control individuals (201B7, 1210B2, and WD39) and CHARGE syndrome patients $(\mathrm{CH} 1$ and $\mathrm{CH} 2)$ were established and maintained as described previously (Takahashi et al. 2007; Okita et al. 2013; Nakagawa et al. 2014; Okuno et al. 2017). The iPSC-derived neural rosette-like structure and brain organoids were generated from $201 \mathrm{~B} 7$ as described previously (Lancaster et al. 2013; Isoda et al. 2016). The AF22 NE cell line was kindly provided by Dr. Austin Smith and maintained as described previously (Falk et al. 2012). The $201 B 7$ and 1210B2 NE cell lines were established from human iPSC lines as described previously (Isoda et al. 2016). The NE cells were passaged every 3-4 d and plated at a ratio of 1:4. The cells were dissociated using TrypLE Select (Thermo Fisher) and plated on Matrigel (Corning)-coated dishes in lt-NES medium (DMEM/ F12 [Wako], 2 mM L-glutamine [Nacalai Tesque], $1.6 \mathrm{mg} / \mathrm{mL}$ glucose [Nacalai Tesque], $0.1 \mathrm{mg} / \mathrm{mL}$ penicillin/streptomycin [Nacalai Tesque], N2 supplement [1:100; Thermo Fisher], $1 \mu \mathrm{L} / \mathrm{mL}$ B27 [Thermo Fisher]) or RHB-A medium (Takara) supplemented with $10 \mathrm{ng} / \mathrm{mL}$ EGF (Peprotech) and $7.5 \mu \mathrm{L} / \mathrm{mL}$ StemBeads FGF2 (Stem Cultures). Details regarding the generation of AF22 cells stably expressing mutant CHD7 and patient NE cells stably expressing wild-type CHD7 are in the Supplemental Material. The HEK293T cell line was grown in high-glucose DMEM (Nacalai Tesque) supplemented with $10 \%$ fetal bovine serum (FBS) (Sigma), $0.1 \mathrm{mg} / \mathrm{mL}$ penicillin/streptomycin, and $1 \mathrm{mM}$ sodium pyruvate (Sigma).

\section{Neuronal differentiation of NE cells}

The NE cells were first cultured in N2B27 medium consisting of a 1:1 ratio of DMEM/F12 and neurobasal medium (Life Technologies) supplemented with N2 supplement (1:200), GlutaMAX (1:100; GIBCO), $0.8 \mathrm{mg} / \mathrm{mL}$ glucose, $0.1 \mathrm{mg} / \mathrm{mL}$ penicillin/streptomycin, B27 (1:100), and $3 \mu \mathrm{M}$ CHIR99021 (Stemgent) for $6 \mathrm{~d}$. At day 6 of CHIR treatment, the cells were passaged and replated onto poly-L-ornithine-coated (Sigma) and laminin-coated (Thermo Fisher) dishes in KBM neural stem cell medium (Kohjin Bio) containing B27 (1:50) supplemented with $1 \mu$ M CHIR99021. The next day, the medium was replaced with KBM neural stem cell medium supplemented with $10 \mathrm{ng} / \mathrm{mL}$ BDNF (R\&D), $10 \mathrm{ng} / \mathrm{mL}$ GDNF (R\&D), $200 \mu \mathrm{M}$ ascorbic acid (Sigma), and $500 \mu \mathrm{M}$ db-cAMP (neurogenic differentiation medium) (Sigma) and cultured for another $9 \mathrm{~d}$. The medium was changed every other day.

\section{Lentiviral production and transduction}

To generate CHD7, BRN2, and SOX21 knockdown cells, we transduced human NE cells with lentiviruses expressing shRNA targeting CHD7, BRN2, and SOX21, respectively. All shRNA vectors were purchased from Sigma (for details, see Supplemental Table S6). For rescue experiments, the cDNAs of human SOX21 (GenBank: NM_007084.2) and BRN2 (GenBank: NM_005604.3) were cloned into the pENTR-D-TOPO vector (Invitrogen). Using LR reaction (Invitrogen), the cDNAs were inserted into the CSIVCBh-RfA-IRES2-HygR construct. Lentiviral packaging plasmids pCAG-HIVgp and pCMV-VSV-G-RSV-Rev were cotransfected into HEK293T cells with Gene Juice (Merck) for virus production. Lentiviral supernatant was collected $48 \mathrm{~h}$ after transfection and supplemented with $4 \mu \mathrm{g} / \mathrm{mL}$ polybrene, filtered through a 0.45 $\mu \mathrm{m}$ filter, and used to infect human NE cells. At $48 \mathrm{~h}$ after infection, the cells were selected with either $1 \mu \mathrm{g} / \mathrm{mL}$ puromycin
(Nacalai Tesque) or a combination of $1 \mu \mathrm{g} / \mathrm{mL}$ puromycin and $80 \mu \mathrm{g} / \mathrm{mL}$ hygromycin (Sigma).

Immunocytochemistry

Cells were washed with PBS, fixed in $4 \%$ paraformaldehyde at room temperature for $15 \mathrm{~min}$, and rinsed three times with PBS. After the cells were blocked with PBS solution containing 3\% FBS and $0.1 \%$ Triton X-100, they were incubated with primary antibodies overnight at $4^{\circ} \mathrm{C}$. Fluorescent marker (Cy2, Cy3, or Cy5)-conjugated secondary antibodies (Jackson Laboratory) were used to label each primary antibody for $2 \mathrm{~h}$ at room temperature. Nuclei were stained with H33258 (Nacalai Tesque). Samples were viewed and photographed using either a Zeiss Axioplan 2 fluorescence microscope or Zeiss confocal laser scanning microscope (LSM 700). Detailed information for primary antibodies is summarized in Supplemental Table S6.

\section{Immunohistochemistry}

E10.5 whole embryos were washed with PBS, fixed in $4 \%$ paraformaldehyde at room temperature for $30 \mathrm{~min}$, and rinsed three times with PBS. Whole embryos were cryoprotected in $30 \%$ sucrose in PBS overnight at $4^{\circ} \mathrm{C}$ and then embedded in OCT compound. Cryostat sections $(12 \mu \mathrm{m})$ were cut and affixed to APScoated glass slides (Matsunami Glass). The sections were then blocked with PBS containing 5\% FBS, $1 \%$ albumin, and $0.25 \%$ Triton X-100 for $1 \mathrm{~h}$ at room temperature. The sections were incubated with primary antibodies overnight at $4^{\circ} \mathrm{C}$. Fluorescent marker (Cy2, Сy3, or Cy5)-conjugated secondary antibodies (Jackson Laboratory) were used to label each primary antibody at room temperature for $2 \mathrm{~h}$. Optical sections were viewed using a Zeiss confocal laser scanning microscope (LSM 700) with 20x and 40x objectives. Detailed information for primary antibodies is summarized in Supplemental Table S6.

\section{Simple Western}

We used a Simple Western system (Simon, ProteinSimple), a nongel-based Western blot-like substitute, to analyze protein expression. The preparation of samples and antibodies and loading of reagents were performed as instructed by the ProteinSimple user manual. Automated separation electrophoresis and chemiluminescence detection were performed using a ProteinSimple WES instrument. The resulting digital images were analyzed with Compass software (ProteinSimple). Detailed information for primary antibodies is summarized in Supplemental Table S6.

\section{$R N A$ isolation and $q R T-P C R$}

Total RNAs were extracted using a RNeasy minikit (Qiagen). cDNAs were synthesized from $1 \mu \mathrm{g}$ of total RNA with a ReverTra Ace qPCR RT kit (Toyobo) according to the manufacturer's instructions. qPCR analysis was performed using a ViiA7 system (Applied Biosystems) with Fast SYBR Green master mix (Thermo Fisher). The expression of target genes was normalized to that of glyceraldehyde 3-phosphate dehydrogenase. The primers used are listed in Supplemental Table S7.

Quartz sequencing (Quartz-seq)

Quartz-seq experiments were carried out as described previously (Sasagawa et al. 2013). See the Supplemental Material for more information. 
Chai et al.

\section{Microarray analysis}

RNA quality was assessed with an Agilent RNA 6000 Nano kit and processed on an Agilent 2100 Bioanalyzer. All RNA samples were amplified and labeled using a TargetAmp-Nano labeling kit (Epicentre). The samples were hybridized to Illumina HumanHT12 v4 Expression BeadChip arrays. Biological duplicates were collected for each sample. Bioinformatics details are included in the Supplemental Material.

\section{ChIP and ChIP-seq}

ChIP was performed as mentioned in (for details, see the Supplemental Material; Asano et al. 2009). Immunoprecipitated DNA was purified using a ChIP DNA clean and concentrator kit (Zymo Research). ChIP-seq libraries were prepared from 3-5 ng of ChIP-enriched DNA using KAPA Hyper preparation kit (Kapa Biosystems) and sequenced using a HiSeq 2500 (Illumina). Bioinformatics details are included in the Supplemental Material.

Reporter cloning and luciferase assay

Selected genomic regions spanning the human SOX21 and BRN2 genes were amplified from the genomic DNA of AF22 cells and cloned into a pGL3 promoter vector (Promega). Primers used for cloning and the coordinates corresponding to $\mathrm{CHD} 7$ peaks are listed in Supplemental Table S7. Reporter vectors were cotransfected with pEF-Renilla-luc (Nakashima et al. 1999) at a ratio of 20:1 using Viafect transfection reagent (Promega) into AF22 cells transduced with either control or CHD7-shRNA pLKO-lentiviral vectors. The medium was replaced with fresh medium after overnight incubation, and luminescence was measured $48 \mathrm{~h}$ after transfection using a dual-luciferase reporter assay system (Promega). Firefly luciferase activity was normalized to Renilla luciferase activity and expressed as fold change relative to control knockdown samples.

\section{Statistical analysis}

All analyses presented in this study were conducted using GraphPad Prism 7. Values are expressed as the mean \pm SEM. When comparing two groups, statistical significance was determined using unpaired two-tailed Student's $t$-test. When comparing multiple groups, one-way analysis of variance (ANOVA) was performed with multiple comparisons followed by Bonferroni analysis.

\section{Accession numbers}

Microarray, RNA-seq, and ChIP-seq data have been deposited in the NCBI Gene Expression Omnibus (GEO; http://www.ncbi. nlm.gov.geo) and are accessible through GEO series accession numbers GSE89951, GSE108170, GSE108275, and GSE108506.

\section{Acknowledgments}

We thank Dr. Austin Smith (University of Cambridge) for providing AF22, Dr. Shinya Yamanaka (Kyoto University) for providing human iPSC clones (201B7 and 1210B2), and Dr. H. Miyoshi (Keio University) for the lentiviral vectors. We also thank the members of H. Okano's laboratories for helpful comments, and Dr. Douglas Sipp for proofreading the manuscript. This work was supported by the Japan Society for the Promotion of Science KAKENHI grant numbers JP16K15240 and JP26713047 to J.K. This research was also supported by research funding from Eisai Co., Ltd. (to H. Okano.), the Research Project for Practical Application of Re- generative Medicine from the Japan Agency for Medical Research and Development (AMED; to J.K.), the Research Center Network for Realization of Regenerative Medicine from the Japan Sciences and Technology Agency (JST), and AMED (to I.N. and H. Okano.). This research is partially supported by the Platform Project for Supporting Drug Discovery and Life Science Research (Platform for Drug Discovery, Informatics, and Structural Life Science) from the Ministry of Education, Culture, Sports, Science and Technology and AMED (to I.N.).

\section{References}

Achilleos A, Trainor PA. 2012. Neural crest stem cells: discovery, properties and potential for therapy. Cell Res 22: 288-304.

Adam RC, Yang H, Rockowitz S, Larsen SB, Nikolova M, Oristian DS, Polak L, Kadaja M, Asare A, Zheng D, et al. 2015. Pioneer factors govern super-enhancer dynamics in stem cell plasticity and lineage choice. Nature 521: 366-370.

Asano H, Aonuma M, Sanosaka T, Kohyama J, Namihira M, Nakashima K. 2009. Astrocyte differentiation of neural precursor cells is enhanced by retinoic acid through a change in epigenetic modification. Stem Cells 27: 2744-2752.

Bajpai R, Chen DA, Rada-Iglesias A, Zhang J, Xiong Y, Helms J, Chang CP, Zhao Y, Swigut T, Wysocka J. 2010. CHD7 cooperates with PBAF to control multipotent neural crest formation. Nature 463: 958-962.

Bronner-Fraser M, Fraser SE. 1988. Cell lineage analysis reveals multipotency of some avian neural crest cells. Nature 335: 161-164.

Bronner-Fraser M, Fraser S. 1989. Developmental potential of avian trunk neural crest cells in situ. Neuron 3: 755-766.

Brown JM, Storey KG. 2000. A region of the vertebrate neural plate in which neighbouring cells can adopt neural or epidermal fates. Curr Biol 10: 869-872.

Chai Y, Jiang X, Ito Y, Bringas P Jr, Han J, Rowitch DH, Soriano P, McMahon AP, Sucov HM. 2000. Fate of the mammalian cranial neural crest during tooth and mandibular morphogenesis. Development 127: 1671-1679.

Cheung M, Briscoe J. 2003. Neural crest development is regulated by the transcription factor Sox9. Development 130: 5681-5693.

Cheung M, Chaboissier MC, Mynett A, Hirst E, Schedl A, Briscoe J. 2005. The transcriptional control of trunk neural crest induction, survival, and delamination. Dev Cell 8: 179-192.

Cong L, Ran FA, Cox D, Lin S, Barretto R, Habib N, Hsu PD, Wu X, Jiang W, Marraffini LA, et al. 2013. Multiplex genome engineering using CRISPR/Cas systems. Science 339: 819-823.

Creyghton MP, Cheng AW, Welstead GG, Kooistra T, Carey BW, Steine EJ, Hanna J, Lodato MA, Frampton GM, Sharp PA, et al. 2010. Histone H3K27ac separates active from poised enhancers and predicts developmental state. Proc Natl Acad Sci 107: 21931-21936.

Curchoe CL, Russo J, Terskikh AV. 2012. hESC derived neuro-epithelial rosettes recapitulate early mammalian neurulation events; an in vitro model. Stem Cell Res 8: 239-246.

Doudna JA, Charpentier E. 2014. Genome editing. The new frontier of genome engineering with CRISPR-Cas9. Science 346: 1258096.

Engelen E, Akinci U, Bryne JC, Hou J, Gontan C, Moen M, Szumska D, Kockx C, van Ijcken W, Dekkers DH, et al. 2011. Sox2 cooperates with Chd7 to regulate genes that are mutated in human syndromes. Nat Genet 43: 607-611.

Falk A, Koch P, Kesavan J, Takashima Y, Ladewig J, Alexander M, Wiskow O, Tailor I, Trotter M, Pollard S, et al. 2012. Capture 
of neuroepithelial-like stem cells from pluripotent stem cells provides a versatile system for in vitro production of human neurons. PLoS One 7: e29597.

Feng W, Khan MA, Bellvis P, Zhu Z, Bernhardt O, Herold-Mende C, Liu HK. 2013. The chromatin remodeler CHD7 regulates adult neurogenesis via activation of SoxC transcription factors. Cell Stem Cell 13: 62-72.

Feng W, Kawauchi D, Korkel-Qu H, Deng H, Serger E, Sieber L, Lieberman JA, Jimeno-Gonzalez S, Lambo S, Hanna BS, et al. 2017. Chd7 is indispensable for mammalian brain development through activation of a neuronal differentiation programme. Nat Commun 8: 14758.

Frank E, Sanes JR. 1991. Lineage of neurons and glia in chick dorsal root ganglia: analysis in vivo with a recombinant retrovirus. Development 111: 895-908.

Fukuta M, Nakai Y, Kirino K, Nakagawa M, Sekiguchi K, Nagata S, Matsumoto Y, Yamamoto T, Umeda K, Heike T, et al. 2014. Derivation of mesenchymal stromal cells from pluripotent stem cells through a neural crest lineage using small molecule compounds with defined media. PLoS One 9: e112291.

Habib N, Li Y, Heidenreich M, Swiech L, Avraham-Davidi I, Trombetta JJ, Hession C, Zhang F, Regev A. 2016. Div-Seq: single-nucleus RNA-seq reveals dynamics of rare adult newborn neurons. Science 353: 925-928.

Hagiwara K, Obayashi T, Sakayori N, Yamanishi E, Hayashi R, Osumi N, Nakazawa T, Nishida K. 2014. Molecular and cellular features of murine craniofacial and trunk neural crest cells as stem cell-like cells. PLoS One 9: e84072.

He D, Marie C, Zhao C, Kim B, Wang J, Deng Y, Clavairoly A, Frah M, Wang $\mathrm{H}, \mathrm{He} \mathrm{X}$, et al. 2016. Chd7 cooperates with Sox 10 and regulates the onset of CNS myelination and remyelination. Nat Neurosci 19: 678-689.

Heinz S, Benner C, Spann N, Bertolino E, Lin YC, Laslo P, Cheng JX, Murre C, Singh H, Glass CK. 2010. Simple combinations of lineage-determining transcription factors prime cis-regulatory elements required for macrophage and B cell identities. Mol Cell 38: 576-589.

Hill RE, Jones PF, Rees AR, Sime CM, Justice MJ, Copeland NG, Jenkins NA, Graham E, Davidson DR. 1989. A new family of mouse homeo box-containing genes: molecular structure, chromosomal location, and developmental expression of Hox-7.1. Genes Dev 3: 26-37.

Hnisz D, Abraham BJ, Lee TI, Lau A, Saint-Andre V, Sigova AA, Hoke HA, Young RA. 2013. Super-enhancers in the control of cell identity and disease. Cell 155: 934-947.

Hsu PD, Lander ES, Zhang F. 2014. Development and applications of CRISPR-Cas9 for genome engineering. Cell 157: 1262-1278.

Isern J, Garcia-Garcia A, Martin AM, Arranz L, Martin-Perez D, Torroja C, Sanchez-Cabo F, Mendez-Ferrer S. 2014. The neural crest is a source of mesenchymal stem cells with specialized hematopoietic stem cell niche function. Elife 3: e03696.

Isoda M, Kohyama J, Iwanami A, Sanosaka T, Sugai K, Yamaguchi R, Matsumoto T, Nakamura M, Okano H. 2016. Robust production of human neural cells by establishing neuroepithelial-like stem cells from peripheral blood mononuclear cellderived feeder-free iPSCs under xeno-free conditions. Neurosci Res 110: 18-28.

Janssen N, Bergman JE, Swertz MA, Tranebjaerg L, Lodahl M, Schoots J, Hofstra RM, van Ravenswaaij-Arts CM, Hoefsloot LH. 2012. Mutation update on the CHD7 gene involved in CHARGE syndrome. Hum Mutat 33: 1149-1160.

Jiang C, Pugh BF. 2009. Nucleosome positioning and gene regulation: advances through genomics. Nat Rev Genet 10: 161-172.
Jiang X, Zhou Y, Xian L, Chen W, Wu H, Gao X. 2012. The mutation in Chd7 causes misexpression of Bmp4 and developmental defects in telencephalic midline. Am $I$ Pathol 181: 626-641.

Johnson DS, Mortazavi A, Myers RM, Wold B. 2007. Genomewide mapping of in vivo protein-DNA interactions. Science 316: $1497-1502$.

Jones KM, Saric N, Russell JP, Andoniadou CL, Scambler PJ, Basson MA. 2015. CHD7 maintains neural stem cell quiescence and prevents premature stem cell depletion in the adult hippocampus. Stem Cells 33: 196-210.

Koch P, Opitz T, Steinbeck JA, Ladewig J, Brustle O. 2009. A rosette-type, self-renewing human ES cell-derived neural stem cell with potential for in vitro instruction and synaptic integration. Proc Natl Acad Sci 106: 3225-3230.

Lancaster MA, Renner M, Martin CA, Wenzel D, Bicknell LS, Hurles ME, Homfray T, Penninger JM, Jackson AP, Knoblich JA. 2013. Cerebral organoids model human brain development and microcephaly. Nature 501: 373-379.

Layman WS, McEwen DP, Beyer LA, Lalani SR, Fernbach SD, Oh E, Swaroop A, Hegg CC, Raphael Y, Martens JR, et al. 2009. Defects in neural stem cell proliferation and olfaction in Chd7 deficient mice indicate a mechanism for hyposmia in human CHARGE syndrome. Hum Mol Genet 18: 1909-1923.

Li W, Sun W, Zhang Y, Wei W, Ambasudhan R, Xia P, Talantova M, Lin T, Kim J, Wang X, et al. 2011. Rapid induction and longterm self-renewal of primitive neural precursors from human embryonic stem cells by small molecule inhibitors. Proc Nat1 Acad Sci 108: 8299-8304.

Nagoshi N, Shibata S, Kubota Y, Nakamura M, Nagai Y, Satoh E, Morikawa S, Okada Y, Mabuchi Y, Katoh H, et al. 2008. Ontogeny and multipotency of neural crest-derived stem cells in mouse bone marrow, dorsal root ganglia, and whisker pad. Cell Stem Cell 2: 392-403.

Nakagawa $M$, Taniguchi $Y$, Senda S, Takizawa N, Ichisaka $T$, Asano K, Morizane A, Doi D, Takahashi J, Nishizawa M, et al. 2014. A novel efficient feeder-free culture system for the derivation of human induced pluripotent stem cells. Sci Rep 4: 3594.

Nakashima K, Yanagisawa M, Arakawa H, Kimura N, Hisatsune T, Kawabata M, Miyazono K, Taga T. 1999. Synergistic signaling in fetal brain by STAT3-Smad1 complex bridged by $\mathrm{p} 300$. Science 284: 479-482.

Nieto MA, Sargent MG, Wilkinson DG, Cooke J. 1994. Control of cell behavior during vertebrate development by Slug, a zinc finger gene. Science 264: 835-839.

Nikitina N, Sauka-Spengler T, Bronner-Fraser M. 2008. Dissecting early regulatory relationships in the lamprey neural crest gene network. Proc Natl Acad Sci 105: 20083-20088.

Okita K, Yamakawa T, Matsumura Y, Sato Y, Amano N, Watanabe A, Goshima N, Yamanaka S. 2013. An efficient nonviral method to generate integration-free human-induced pluripotent stem cells from cord blood and peripheral blood cells. Stem Cells 31: 458-466.

Okuno H, Renault Mihara F, Ohta S, Fukuda K, Kurosawa K, Akamatsu W, Sanosaka T, Kohyama J, Hayashi K, Nakajima K, et al. 2017. CHARGE syndrome modeling using patient-iPSCs reveals defective migration of neural crest cells harboring CHD7 mutations. Elife 6: e21114.

Olsen BR, Reginato AM, Wang W. 2000. Bone development. Annu Rev Cell Dev Biol 16: 191-220.

Remboutsika E, Elkouris M, Iulianella A, Andoniadou CL, Poulou M, Mitsiadis TA, Trainor PA, Lovell-Badge R. 2011. Flexibility of neural stem cells. Front Physiol 2: 16. 
Ronan JL, Wu W, Crabtree GR. 2013. From neural development to cognition: unexpected roles for chromatin. Nat Rev Genet 14: 347-359.

Sandberg M, Kallstrom M, Muhr J. 2005. Sox 11 promotes the progression of vertebrate neurogenesis. Nat Neurosci 8: 995-1001.

Sander JD, Joung JK. 2014. CRISPR-Cas systems for editing, regulating and targeting genomes. Nat Biotechnol 32: 347-355.

Sanlaville D, Verloes A. 2007. CHARGE syndrome: an update. Eur I Hum Genet 15: 389-399.

Sanlaville D, Etchevers HC, Gonzales M, Martinovic J, ClementZiza M, Delezoide AL, Aubry MC, Pelet A, Chemouny S, Cruaud C, et al. 2006. Phenotypic spectrum of CHARGE syndrome in fetuses with CHD7 truncating mutations correlates with expression during human development. J Med Genet 43: 211-217.

Sasagawa Y, Nikaido I, Hayashi T, Danno H, Uno KD, Imai T, Ueda HR. 2013. Quartz-seq: a highly reproducible and sensitive single-cell RNA sequencing method, reveals non-genetic gene-expression heterogeneity. Genome Biol 14: R31.

Sauka-Spengler T, Bronner-Fraser M. 2008. A gene regulatory network orchestrates neural crest formation. Nat Rev Mol Cell Biol 9: 557-568.

Savic D, Partridge EC, Newberry KM, Smith SB, Meadows SK, Roberts BS, Mackiewicz M, Mendenhall EM, Myers RM. 2015. CETCh-seq: CRISPR epitope tagging ChIP-seq of DNA-binding proteins. Genome Res 25: 1581-1589.

Scherson T, Serbedzija G, Fraser S, Bronner-Fraser M. 1993. Regulative capacity of the cranial neural tube to form neural crest. Development 118: 1049-1062.

Schnetz MP, Bartels CF, Shastri K, Balasubramanian D, Zentner GE, Balaji R, Zhang X, Song L, Wang Z, Laframboise T, et al. 2009. Genomic distribution of CHD7 on chromatin tracks H3K4 methylation patterns. Genome Res 19: 590-601.

Schnetz MP, Handoko L, Akhtar-Zaidi B, Bartels CF, Pereira CF, Fisher AG, Adams DJ, Flicek P, Crawford GE, Laframboise T, et al. 2010. CHD7 targets active gene enhancer elements to modulate ES cell-specific gene expression. PLoS Genet 6: e1001023.

Selleck MA, Bronner-Fraser M. 1995. Origins of the avian neural crest: the role of neural plate-epidermal interactions. Development 121: 525-538.

Shimojo D, Onodera K, Doi-Torii Y, Ishihara Y, Hattori C, Miwa Y, Tanaka S, Okada R, Ohyama M, Shoji M, et al. 2015. Rapid, efficient, and simple motor neuron differentiation from human pluripotent stem cells. Mol Brain 8: 79.
Simoes-Costa M, Bronner ME. 2013. Insights into neural crest development and evolution from genomic analysis. Genome Res 23: 1069-1080.

Takahashi K, Tanabe K, Ohnuki M, Narita M, Ichisaka T, Tomoda K, Yamanaka S. 2007. Induction of pluripotent stem cells from adult human fibroblasts by defined factors. Cell 131: 861-872.

Takashima Y, Era T, Nakao K, Kondo S, Kasuga M, Smith AG, Nishikawa S. 2007. Neuroepithelial cells supply an initial transient wave of MSC differentiation. Cell 129: 1377-1388.

Thomas S, Thomas M, Wincker P, Babarit C, Xu P, Speer MC, Munnich A, Lyonnet S, Vekemans M, Etchevers HC. 2008. Human neural crest cells display molecular and phenotypic hallmarks of stem cells. Hum Mol Genet 17: 3411-3425.

Vierbuchen T, Ostermeier A, Pang ZP, Kokubu Y, Sudhof TC, Wernig M. 2010. Direct conversion of fibroblasts to functional neurons by defined factors. Nature 463: 1035-1041.

Visel A, Minovitsky S, Dubchak I, Pennacchio LA. 2007. VISTA Enhancer Browser-a database of tissue-specific human enhancers. Nucleic Acids Res 35: D88-D92.

Vissers LE, van Ravenswaaij CM, Admiraal R, Hurst JA, de Vries BB, Janssen IM, van der Vliet WA, Huys EH, de Jong PJ, Hamel $\mathrm{BC}$, et al. 2004. Mutations in a new member of the chromodomain gene family cause CHARGE syndrome. Nat Genet 36: 955-957.

Whyte WA, Orlando DA, Hnisz D, Abraham BJ, Lin CY, Kagey MH, Rahl PB, Lee TI, Young RA. 2013. Master transcription factors and mediator establish super-enhancers at key cell identity genes. Cell 153: 307-319.

Wiszniak S, Mackenzie FE, Anderson P, Kabbara S, Ruhrberg C, Schwarz Q. 2015. Neural crest cell-derived VEGF promotes embryonic jaw extension. Proc Natl Acad Sci 112: 6086-6091.

Yu T, Meiners LC, Danielsen K, Wong MT, Bowler T, Reinberg D, Scambler PJ, van Ravenswaaij-Arts CM, Basson MA. 2013. Deregulated FGF and homeotic gene expression underlies cerebellar vermis hypoplasia in CHARGE syndrome. Elife 2: e01305.

Yu M, Yang W, Ni T, Tang Z, Nakadai T, Zhu J, Roeder RG. 2015. RNA polymerase II-associated factor 1 regulates the release and phosphorylation of paused RNA polymerase II. Science 350: 1383-1386.

Zentner GE, Layman WS, Martin DM, Scacheri PC. 2010. Molecular and phenotypic aspects of CHD7 mutation in CHARGE syndrome. Am J Med Genet A 152A: 674-686. 


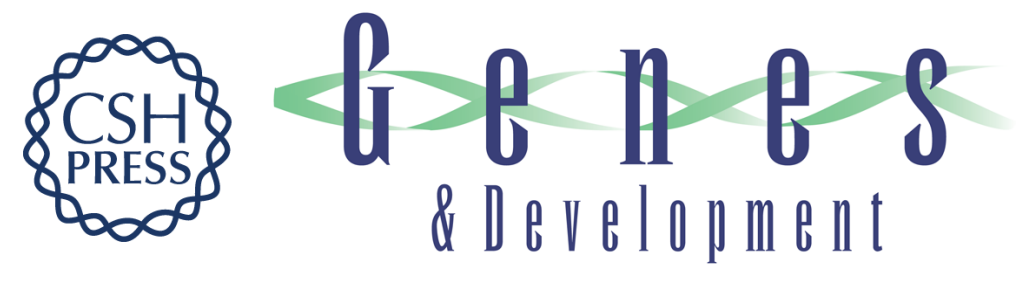

\section{Chromatin remodeler CHD7 regulates the stem cell identity of human neural progenitors}

MuhChyi Chai, Tsukasa Sanosaka, Hironobu Okuno, et al.

Genes Dev. 2018, 32: originally published online February 9, 2018

Access the most recent version at doi:10.1101/gad.301887.117

\section{Supplemental http://genesdev.cshlp.org/content/suppl/2018/02/09/gad.301887.117.DC1 Material}

References This article cites 72 articles, 22 of which can be accessed free at: http://genesdev.cshlp.org/content/32/2/165.full.html\#ref-list-1

Creative This article is distributed exclusively by Cold Spring Harbor Laboratory Press for the first Commons six months after the full-issue publication date (see

License http://genesdev.cshlp.org/site/misc/terms.xhtml). After six months, it is available under a Creative Commons License (Attribution-NonCommercial 4.0 International), as described at http://creativecommons.org/licenses/by-nc/4.0/.

Email Alerting Receive free email alerts when new articles cite this article - sign up in the box at the top Service right corner of the article or click here.

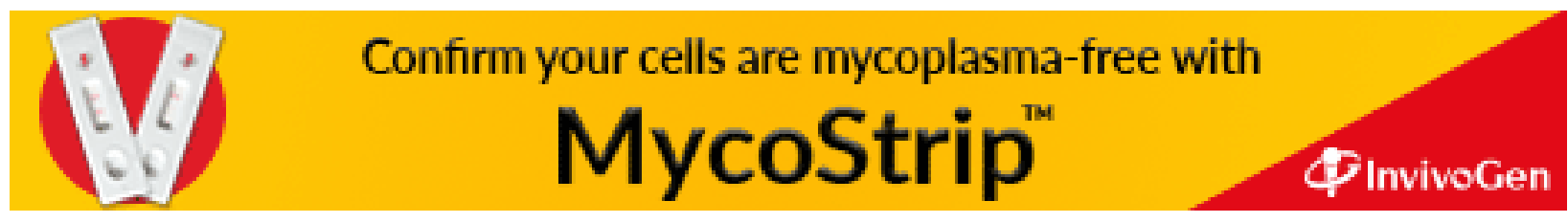

